\title{
OBSERVATIONS ON THE BIOLOGY AND POST- EMBRYONIC DEVELOPMENT OF IDOTEA VIRIDIS (SLABBER) (ISOPODA, VALVIFERA) FROM NEW ENGLAND CREEK, SOUTH-EAST ESSEX
}

\author{
By N. H. Howes, M.Sc. \\ Department of Zoology and Comparative Anatomy, \\ University College, University of London
}

(Text-figs. I-I4)

CONTENTS

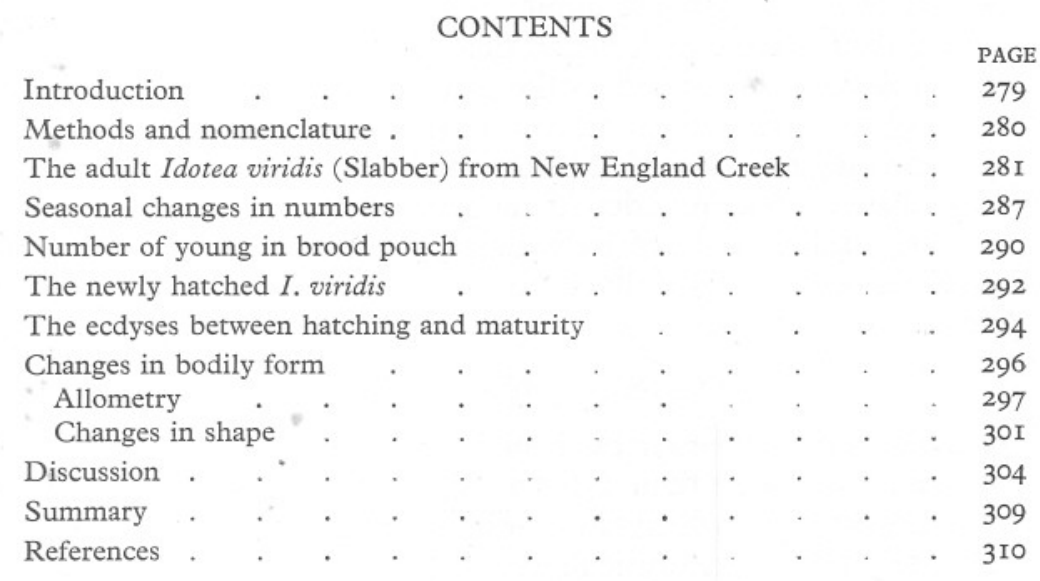

\section{INTRODUCTION}

In the course of an ecological survey of a saline lagoon, New England Creek in south-east Essex (Howes, 1939), it was found that one of the dominant species of animals present was a form, possibly a local race, of Idotea viridis. New England Creek runs from the Yokefleet, a branch of the River Roach, on to the Maplin Sands. It was dammed at both ends in 1925 while still full of water, and by 1934 had become a lagoon containing approximately $250,000 \mathrm{cu}$. m. of water of lower salinity than, and of a slightly different composition from, sea water (Howes, 1939). The lagoon was visited at regular intervals, usually about every four weeks, throughout 1934, I935 and 1936, samples of the water being taken for analysis and specimens of the fauna collected at each visit. Further, a standard haul was made with a plankton net on each occasion. The $I$. viridis proved to be an active swimmer and, apart from specimens collected by hand, over eight thousand in all were taken 
in the plankton alone. Thus a collection was made which included all stages in the post-embryonic development of this species and, since it was well preserved, provided excellent material for studying its biology.

The species $I$. viridis appears to contain animals showing a wide range of morphological variation, especially between individuals collected from different localities, i.e. there appear to be well-defined local races of which the New England Creek form may be one. Since the latter does not exactly tally with the earlier accounts of $I$. viridis, a detailed description was deemed advisable before discussing its biology. After this description, the paper deals first with the annual change in numbers of $I$. viridis, the number of eggs in the brood pouch and the distribution of different size groups in the plankton hauls throughout 1936. The nature of these phenomena may be peculiar to this race. Following this, the newly hatched animal is described, and then the change in shape of the body, the coxal plates and of certain appendages, as the animal develops into the adult. Although the material suffers from being derived from a form of $I$. viridis that may not be common in England, which may, indeed, be confined to the lagoon, New England Creek and to dykes draining into that creek, nevertheless it is believed that the results of this latter investigation recorded below are, in a modified degree, applicable to the Idoteidae as a whole. Idoteids appear rarely to be found together in large numbers, and a series of individuals, representing every instar from hatching to maturity, is so difficult to obtain that little is known of their development.

\section{METHODS AND NOMENCLATURE}

The animals were collected by hand and with nẹts, the majority with a plankton net. They were then killed and fixed by the addition of sufficient formalin to the water in which they were, to produce a final concentration of approximately $5 \%$. Fixed animals were used for all measurements recorded. The animal was placed on a well slide in water, lightly pressed flat by means of a cover-slip or piece of slide, lighted from above and measured to the nearest $\frac{1}{100} \mathrm{~mm}$. by means of a travelling microscope at a magnification of 20 diameters; for animals of the first and second instars, an eyepiece micrometer was substituted for the travelling microscope. Apart from errors inherent in the method owing to distortion on fixation, measurements made of the same animal on different occasions showed that an accuracy of well within $\pm 2 \%$ was usually attained.

For morphological studies, animals or appendages were mounted untreated in Canada balsam or Gurr's water mounting medium: specimens were also heated over a boiling water bath in $2 \%$ caustic soda and the chitinous skeleton obtained then mounted in Canada balsam. In regard to the nomenclature of the three main divisions of the body, I have followed Calman (1909) since there seems to be no reason to suppose that they are other than homologous with the corresponding regions of the Malacostraca as a whole, and 
have $\mathrm{c}$ led them, cephalon, thorax and abdomen, discarding the arachnidan terms ised by Sars (1899) and Collinge (I917), namely cephalon, mesosome and metasome, respectively. Following the nomenclature customary in Isopoda, the first free thoracic segment is referred to as the first thoracic segment and the remaining segments numbered accordingly. Needham (1937), to whose work considerable reference is made, calls the first free thoracic somite the second thoracic segment. In the light of more recent work, Collinge's "lateral clefts" of the cephalon are referred to as "occipital grooves" and that part of the cephalon lying behind them as the "maxillipedal somite" (Jackson, I926). The names of the joints of the maxillipedes are taken from Hansen (1925), the lateral half of Collinge's (I918) divided coxopodite then becoming the proximal epipodite and the median half the coxa proper. The use of the term "fused dactylus and carpo-propus" for the distal joint of the maxillipedal palp may be quite unjustified, but since it was necessary to refer to individual joints by name, I have taken the liberty of thus modifying Hansen's description of the maxillipede of Glyptonotus; it is not claimed that this is a correct homology, but the knee is definitely situated between the two distal joints in the species described above. All the illustrations in this paper are made from individual specimens and no attempt has been made to produce generalized diagrams, hence slight variations in shape are to be expected. It should be noticed that there are considerable variations in size in each instar.

\section{The Adult IDotea Viridis (Slabber) From New England Creek}

Body narrow, elongated (Fig. I), about 4.6 times as long as broad; dorsal surface moderately convex, surface either smooth or pitted. Cephalon (Fig. 2a) wider than long, ratio breadth/length, males $1 \cdot 45 \pm 0.12$ (I20 specimens), females I $\cdot 48 \pm 0 \cdot 12$ ( 45 specimens); anterior margin slightly emarginate, posterior margin straight; lateral margin with slight fissure at point of demarcation of the maxillipedal somite from rest of cephalon; fissure continued as stronglymarked occipital groove, extending one-quarter of width of cephalon inwards, not visible in mid-line; maxillipedal somite about one-fifth length of cephalon, lateral borders tapering to an antero-lateral blunt point faintly divided by groove. Eyes large, length about one-third cephalon, situated dorso-laterally, posterior margin on median transverse line of cephalon. Antennulae (Fig. 2b) extending well beyond third peduncular joint of antenna, first joint expanded, irregularly angular, second joint nearly as long but narrower, third joint slightly elongated; flagellum (Fig. 2c) single-jointed, clavate, lateral angle acute, antero-medial surface rounded with three or four setae and eight (one isolated lateral, three pairs and one single median) spindle-shaped, pedunculate aesthetascs (Fig. 2d), each with truncate distal tip where pore opens to exterior. Antennae (Fig. 2e) elongated, first peduncular joint very short, with dorsal forwardly directed rounded angle, second longer, incised 
laterally with dorsal forwardly directed obtuse point, third scarcely longer than second, concave distally on both dorsal and ventral surfaces with median and lateral anterior projections, fourth longer than third with dorsal forwardly directed obtuse point and single antero-lateral spine, fifth joint longer and narrower than fourth; flagellum about one and a quarter times length of
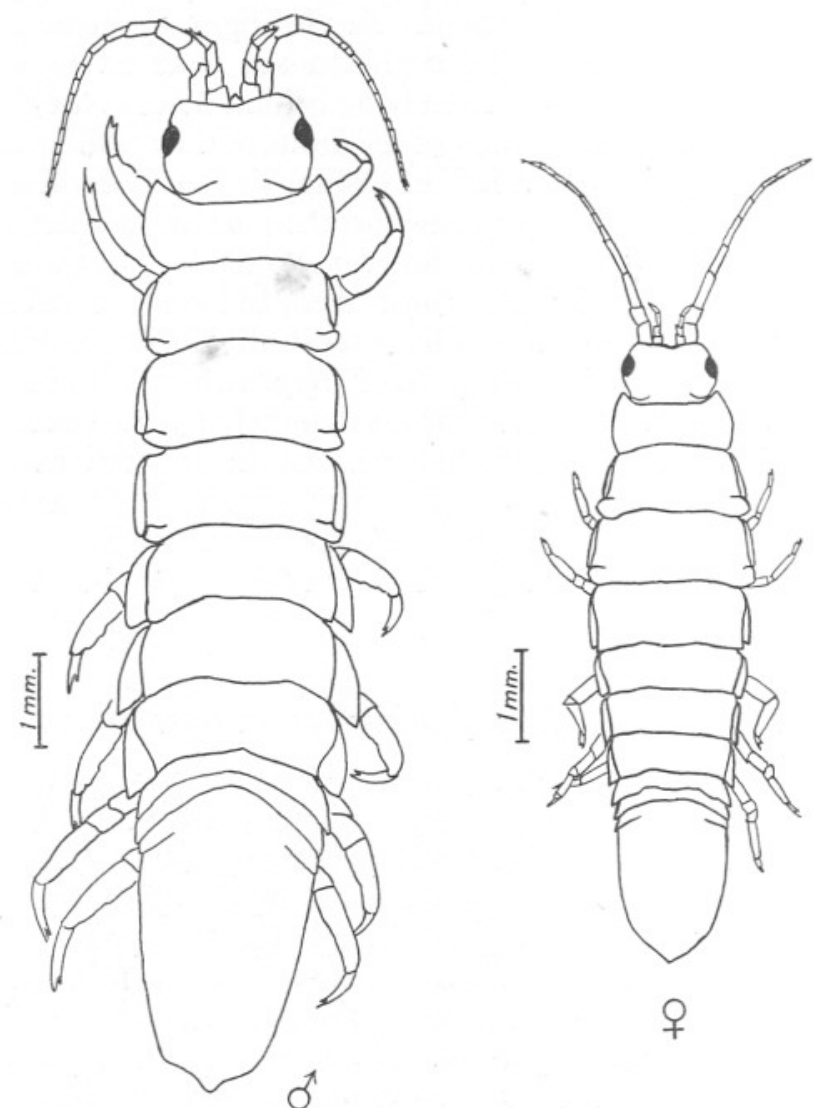

Fig. I. Adult male and female of Idotea viridis (New England Creek, Essex).

peduncle with II to I3 joints in fully grown males, first joint somewhat elongated, terminal style (Fig. $2 f$ ) almost cylindrical, half length of preceding segment. Maxillulae (Fig. $2 g, h$ ): outer lobe terminating in eleven curved spines, six outer (four or five toothed), five inner (three toothed, two median slender and untoothed); inner lobe terminally rounded with three setose spines and small outer spine. Maxillae (Fig. 2j) consisting of two laminar setose lobes, outer bipartite lobe with long ctenate setae, inner lobe with row of setae, three innermost slightly stouter and markedly plumose. Maxilli- 

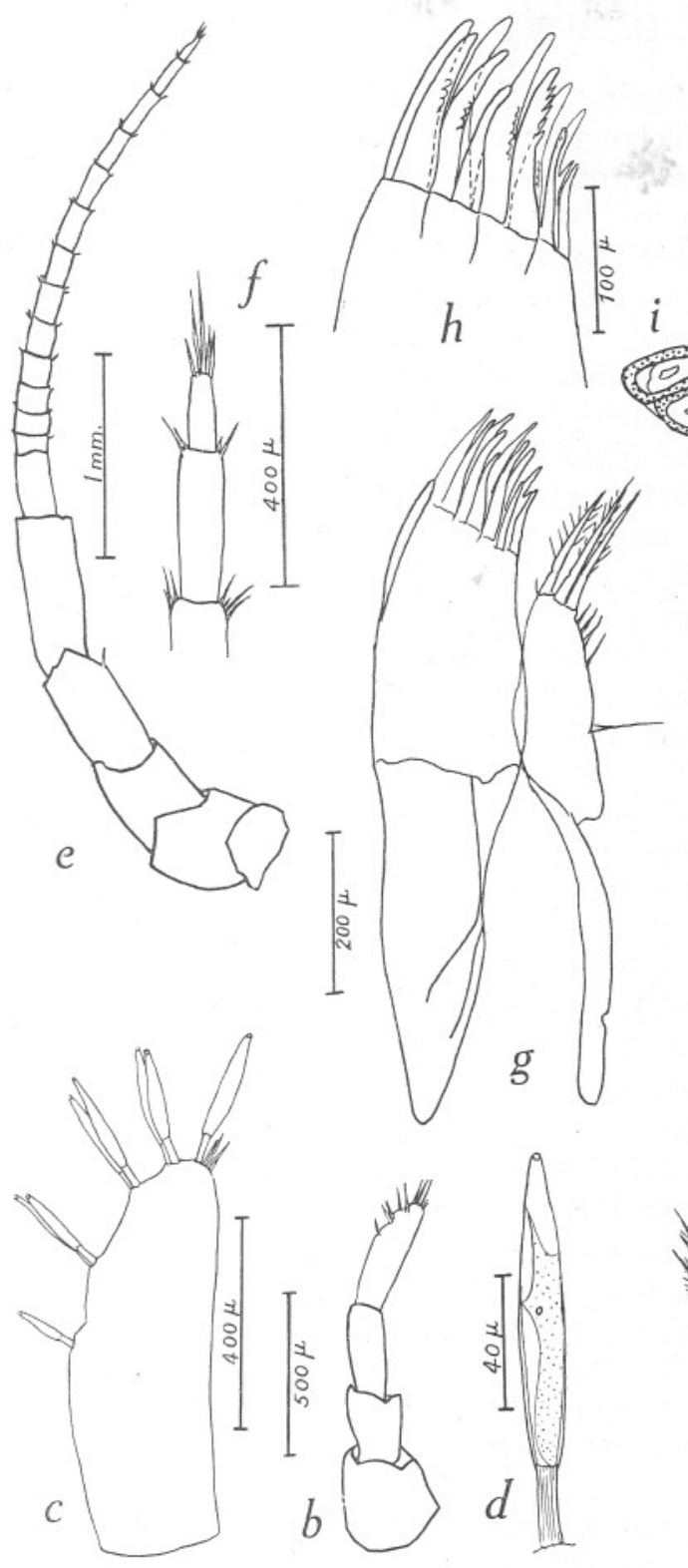
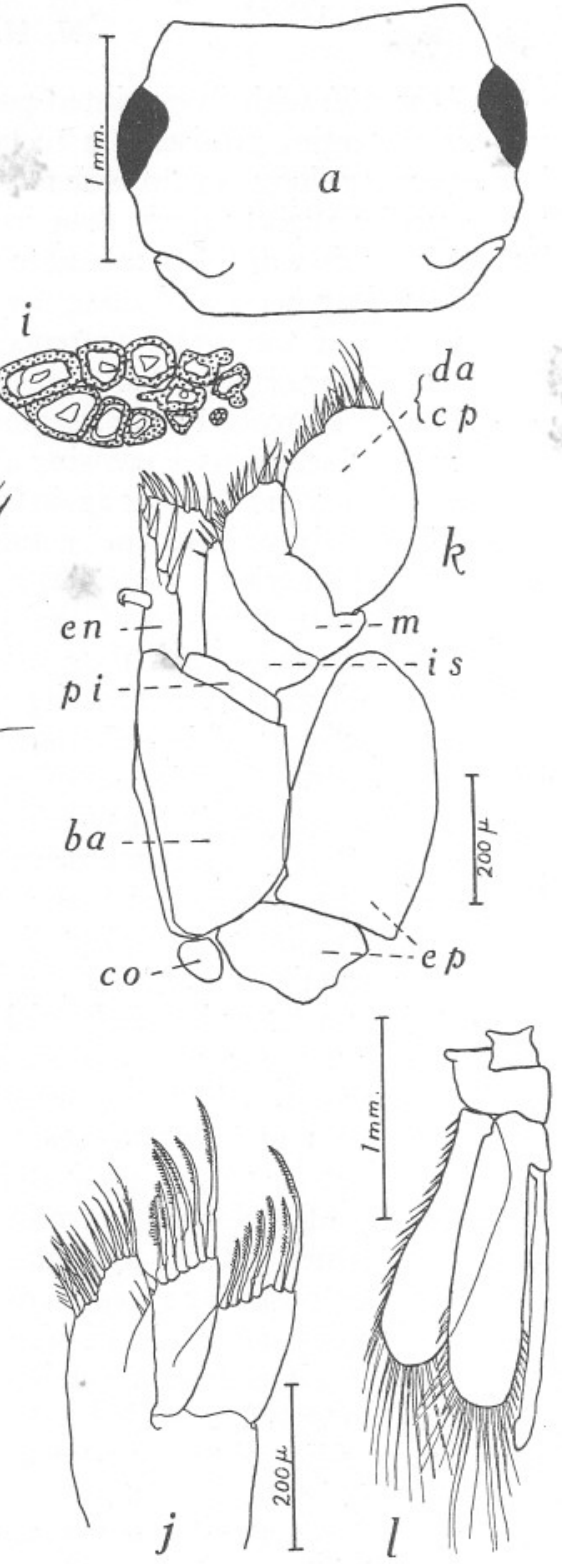

Fig. 2. Idotea viridis (New England Creek, Essex). a, cephalon, dorsal view, I2.5 mm. ô; $b$, right antennula, dorsal view, II mm. $\delta$; $c$, flagellum of right antennula, artificially flattened to show distribution of aesthetascs; $d$, aesthetasc; $e$, right antenna, dorsal view, II mm. $\delta ; f$, terminal setose style of right antenna; $g$, right maxillula, ventral view, I3 mm. 0 ; $h$, tip of outer lobe of right maxillula; $i$, oblique section through maxillula passing transversely through bases of spines, inner side of lobe to the right, dorsal surface at top; $j$, left maxilla, ventral view, I3 mm. $0 ; k$, right maxillipede, ventral view, I3 mm. $\sigma^{*}$; $b a$, basis; $c o$, coxa; $c p$, da, carpo-propus, dactylus; en, endite; ep, epipodites; $i$, ischium; $m$, merus; $p i$, preischium; $l$ second right pleopod, ventral view, $\mathrm{I} 4 \mathrm{~mm}$. $\delta^{\circ}$. (In all cases the appendages are described in their anatomical position.) 
pedes (Fig. $2 k$ ) with four-jointed palp, distal joint of palp with marked nick on inner margin, pre-ischium rectangular when viewed from above; basis large, nearly as long as palp; size ratio of coxa and proximal epipodite variable; tip of endite slightly more than half way up inner border of merus, inner border bent dorsally, hence endite roughly L-shaped in cross-section, with single coupling hook projecting inwards at angle; width of dorsally-directed portion half of transverse flattened region. First, fifth, sixth and seventh segments of thorax (Fig. I) shorter than second, third and fourth; first shortest and seventh scarcely longer; segments two, three and four approximately same length; segments increasing slightly in width up to segments five and six, segment seven narrower again; anterior angles of pleuron of first thoracic segment sharply pointed, projecting laterally beyond borders of head and forward well anterior to occipital groove; in adult males this segment about $20 \%$ wider than cephalon. Coxal plates (Fig. $3 e, f$ ) in two groups, those of segments two, three and four showing only a narrow projection beyond lateral pleural margin, occupying from under three-quarters to over ninetenths respectively of lateral margins of segments, visible right up to and round antero-lateral angles; coxal plates of segments five, six and seven wide, almost triangular, projecting well beyond lateral borders of segment throughout length; coxal plate of segment seven with backwardly projecting acute angle. In segments two, three and four, a small area of pleuron separated from rest by a medially directed transverse slit visible from below; in segments two and three remains of pleuron projecting to lateral border of coxal plates, separated from latter by slight nick; in segment four ending more medially and in segment five scarcely visible. Remaining thoracic appendages (Fig. $3 a, b$ ) similar to those of other members of genus. Abdomen (Figs. I, $3 d$ ) with two short segments and antero-transverse grooves indicating coalesced third, forming about $33.5 \%$ of total body length (anterior border of cephalon to posterior tip of abdomen); terminal fused segment moderately long, $84 \%$ of total abdomen length; total abdomen in intact animal about $\mathrm{I} \cdot 9$ times as long as wide; posterior margin convex with single median tooth and lateral corners forming an angle of about $\mathrm{IIO}^{\circ}$. Appendix masculinus of second pleopods (Fig. 2 l) extending well beyond end of endopodite. Uropoda (Fig. $3 \mathrm{c}$ ) flattened, elongated, rounded anteriorly, slightly broader in middle than at ends, endopodite obtusely truncated; setose style arising from basal plate reaches to tip of endopodite.

Length of animal: adult males, I2-I4 mm.; ovigerous females, $5.5-10.5 \mathrm{~mm}$.

Colour: background generally brown, but not rarely white or with white patches, with variously distributed melanophores giving a large range of different patterns, most commonly with an even distribution. Background remains brown in alcohol.

Distribution: New England Creek and dykes draining into it, near Great Wakering, south-east Essex. This environment has been described in some detail elsewhere (Howes, 1939). The species is very common indeed and it 
is calculated that the creek contains of the order of two and a quarter million individuals when peak numbers are present (Fig. 4).

It is strange that no reference is anywhere made to the fact that the endite of the maxillipede is bent upwards so as to have the inner surfaces in both a horizontal and a vertical plane, thus making the joint L-shaped or triangular
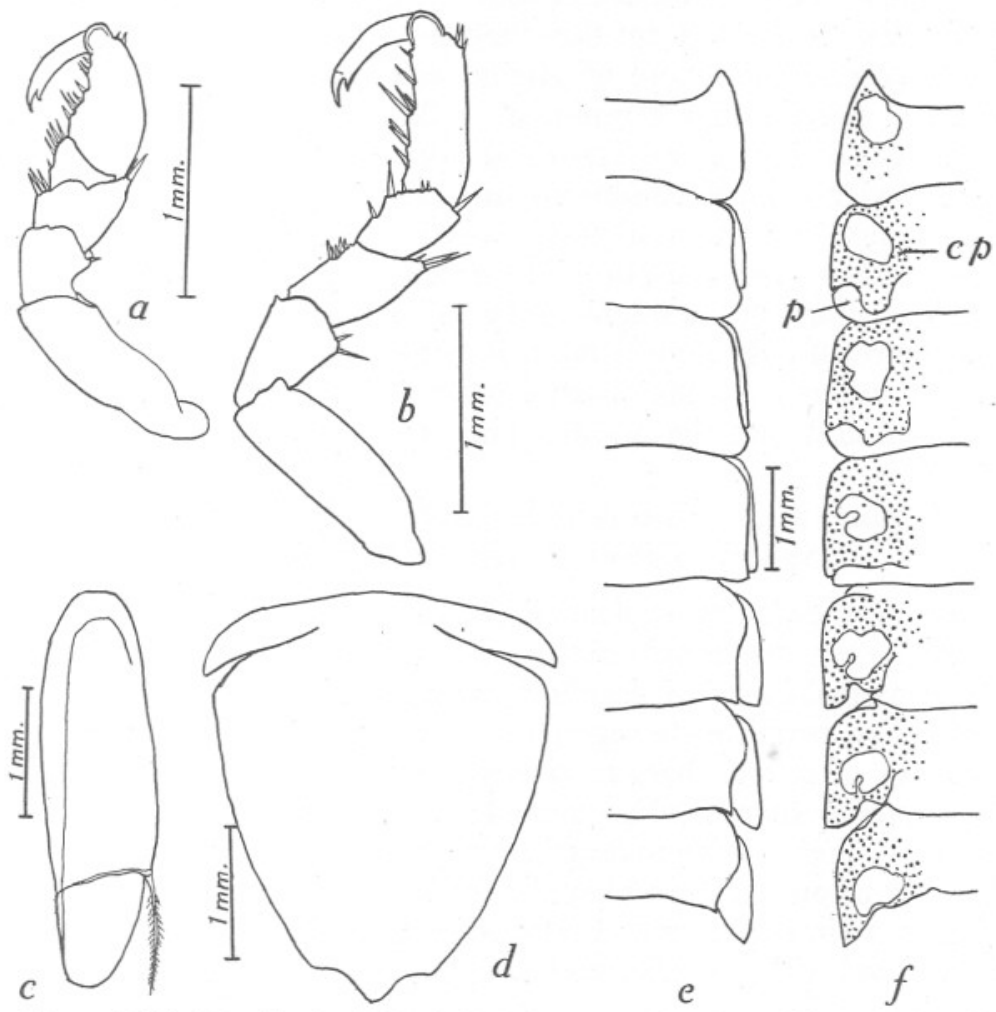

Fig. 3. Idotea viridis (New England Creek, Essex). a, anterior view of first pereiopod, II mm.

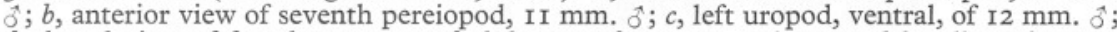
$d$, dorsal view of fused segments of abdomen of $\mathrm{I} 2 \mathrm{~mm}$. $\hat{o}$ (prepared by dissecting out pleopods and soft tissues and pressing abdomen flat); $e$, dorsal view, $f$, ventral view, of coxal plates of $13.4 \mathrm{~mm}$. 0 (preparations made after treatment with caustic soda. Ventral view, coxal plates are dotted); $c p$, coxal plate; $p$, pleuron. (In all cases the appendages are described in their anatomical position.)

in cross-section, with the coupling hook arising from the angle thus made. This condition is probably widespread in the Idoteidae and certainly occurs in I. baltica, I. neglecta, I. emarginata, I. granulosa, and I. linearis, although often to a much less marked degree than in I. viridis.

The aesthetascs of the antennules do not seem to have been observed, but experience has shown that they have the appearance of setae when the appendage is mounted in either Canada balsam or in water mounting medium; 
and in marine forms they are often so covered by ectoparasitic Peritrichida as to be completely obscured. In water their structure can more easily be made out and it was possible to study them in some detail in the I. viridis from New England Creek, where they were scarcely ever parasitized. They closely resemble the "olfactory setae" or "Riechstäbchen" described by Scourfield $(1896,1905)$ in Cladocera and other forms, being shaped like those of, e.g., Daphnia magna, except that they are not divided transversely and are stalked. They resemble those of Asellus aquaticus in being divided into a hyaline distal portion and a proximal stalk with strongly chitinized walls. These aesthetascs have been examined both with ultra-violet and red and blue light under critical conditions and in the position occupied by the "terminal pellet" on the aesthetascs of Cladocera (Scourfield, I905) there is in this species a tiny open pore. The arrangement of the aesthetascs on the flagellum of the antennule might prove to be a useful secondary systematic character, since, if fully grown animals were compared, it was found to be constant. It suffers from the disadvantages that the organs are very liable to be parasitized and that the number and arrangement alters from instar to instar.

\section{Idotea viridis from New England Creek compared with \\ I. viridis (Slabber) as described by Sars (I899)}

Body form somewhat more slender, cephalon wider, frontal margin similar. Eyes appear larger. Antennule similar. Joints of antennary peduncle differing in detail, proximal joints of flagellum shorter and style of flagellum shorter in proportion to penultimate segment. Coxal plates only occupying anterior three-quarters of lateral margins of segments two, three and four and not reaching posterior margin of segment five. Legs similar, joints of PI about $25 \%$ broader in proportion to length, $\mathrm{P}_{7}$ carpus markedly shorter than merus, again broader in proportion to length. Abdomen similar. Stylet of pleopod 2 projecting to a similar extent. Endopodite of uropod more tapering; tip of setose style level with posterior end of uropod.

\section{I. viridis from New England Creek compared with I. viridis (Slabber) as described by Collinge (1917)}

Body shape similar, cephalon proportionately wider, eyes larger. Basal joints of antennules differing in shape and proportions. Antennae: style shorter. Maxillulae: eleven spines (seven or eight, toothed) instead of nine (three, toothed). Characteristically, two median spines slender and untoothed. Except for first, segments of thorax almost equal in length. Coxal plates of segments two, three and four similar but narrower, of segments five, six and seven not contiguous and narrower. Maxillipedes similar; other thoracic appendages, $\mathrm{P}$ I slightly stouter in proportion, propus of $\mathrm{P} 7$ very much stouter, carpus shorter than merus. Abdomen similar. Endopodite of uropod more tapering, setose style reaching posterior tip of endopodite. 
It thus appears that $I$. viridis from New England Creek differs from those described by Sars and by Collinge in many particulars, especially in the size of the eyes, the shape of the style of the antenna, the size of the coxal plates as measured by the lateral expansions visible from the dorsal surface, the build of the peraeopods, the shape of the endopodite of the uropod and the length of the setose style. It further differs from Collinge's description in that the outer lobe of the maxilla terminates in eleven spines instead of nine. But these are characters which appear to vary more or less independently of each other throughout the species. Mr G. M. Spooner kindly lent me his collection of $I$. viridis, which contained specimens from nine different localities, six in the Tamar Estuary, two near Weymouth and one from Holbeach on the Wash, and my collection includes animals from three different habitats near Great Wakering, Essex. On the whole, animals obtained from the same locality closely resemble one another, apart from age and sex differences, but may differ from the $I$. viridis described by Sars, by Collinge or that from New England Creek in some or all of the characters enumerated above, except that every adult male from the two collections had eleven spines on the outer lobe of the maxilla. This last character is not likely to prove of diagnostic value since it occurs commonly throughout the genus (Collinge, I9I7).

There remain three characters which serve to differentiate the species viridis from other members of the genus Idotea and yet include in that species the animals described by Sars and by Collinge as I. viridis, together with the twelve forms mentioned above. These are, in the adult male: (a) body slimly built, with lateral margins almost parallel and with the widest region in the fifth and sixth thoracic segments rather than in the third or fourth as in other species; (b) cephalon with overall breadth only about $\mathrm{I} \cdot 5$ times overall length; (c) abdomen slightly tapering posteriorly, terminating in a single median tooth; obtuse postero-lateral corners very distinctly marked but never projecting backwards as lateral teeth.

This scheme closely follows the points stressed by Sars (I899, p. 84) and it is the basis upon which the Idotea collected in New England Creek are considered to be $I$. viridis.

\section{Seasonal Changes in Numbers}

New England Creek runs from the Yokefleet, a branch of the River Roach, on to the Maplin Sands. It was dammed in I925 and a body of water was enclosed with the intention of draining the creek later on. This has not been done, but the salinity of the water has become reduced and a great many chemical changes have taken place. A fairly detailed study of these changes and of the fauna and flora has been made and is published elsewhere (Howes, I939). The creek in $1934-6$ was about $I_{2} \frac{1}{2}$ miles long, had a maximum depth of $3 \frac{1}{2} \mathrm{~m}$. and a surface area of I44,000-170,000 sq. m., and contained between 
230,000 and $299,000 \mathrm{cu}$. m. of water. The predominant plant species were Ruppia maritima and Chaetomorpha linum, the former occurring in large quantities and reaching the surface.

Idotea viridis was very common, and was found swimming and crawling on the stems of Ruppia. Observations suggest that it eats polyps of Membranipora and of coelenterates, though any dead animal in the creek always had a large number of specimens crawling on it. In cold weather the numbers of Idotea viridis appear to be very much reduced and only a few specimens can be found crawling in weed near the bottom.

The creek was visited once every four weeks, and on each visit a haul was made with a silk plankton net, Ioo strands to $I$ in., over a measured length of $1325 \mathrm{~m}$. Details of this haul and a discussion of its value as a quantitative method are given in an earlier paper (Howes, 1939) and it suffices here to state that approximately $100 \mathrm{cu}$. m. of water were filtered. At the completion of each haul, not only were the contents of the bucket preserved, but the silk was carefully examined, all visible adhering organisms removed with a camel hair brush and added to the catch in the bucket. The number in each catch represents both swimming animals and others swept off surface weed by the net. Results obtained by counting the number of Idotea in each catch for the years 1934, I935, I936 are given in Fig. 4.

The interest of this diagram lies in the paucity in numbers of $I$. viridis in the first five months of the year, the very rapid rise to a maximum in late June and in July and the way in which the numbers remain comparatively high until the end of October, then fall off rapidly, rising again in December. It is believed that the lateness of the attainment of maximum numbers is mainly due to the carnivorous nature of the New England Creek race and that no considerable reproduction occurs until a plentiful supply of coelenterates and especially of Membranipora crustulenta var. fossaria is available. Observation has shown that these forms become common about May and that the Membranipora, at least, continues to be present in quantity until October. The significance of the rise in December is not understood. The method of collecting nekton forms by means of a plankton net towed just below the surface is obviously open to criticism and it is important to enquire how far the picture presented by these data really represents the behaviour of the population in the creek. It is known that all sizes of Idotea, including ovigerous females, are taken in the hauls (Fig. 5), so that the result cannot be entirely due to certain instars retiring beyond the reach of the net. Further, a visit to the creek in late summer or early autumn impresses one with the extraordinary plentifulness of $I$. viridis; on the other hand, in late winter or early spring it is possible to spend a whole day collecting and not see a single specimen unless they are very specially looked for; even dragging weed from the depths will only yield an occasional individual. It can therefore be concluded that Fig. 4 is a fair rough representation of the behaviour of the population as a whole. It can be calculated that at the peak periods in 1934 and 1936 the 


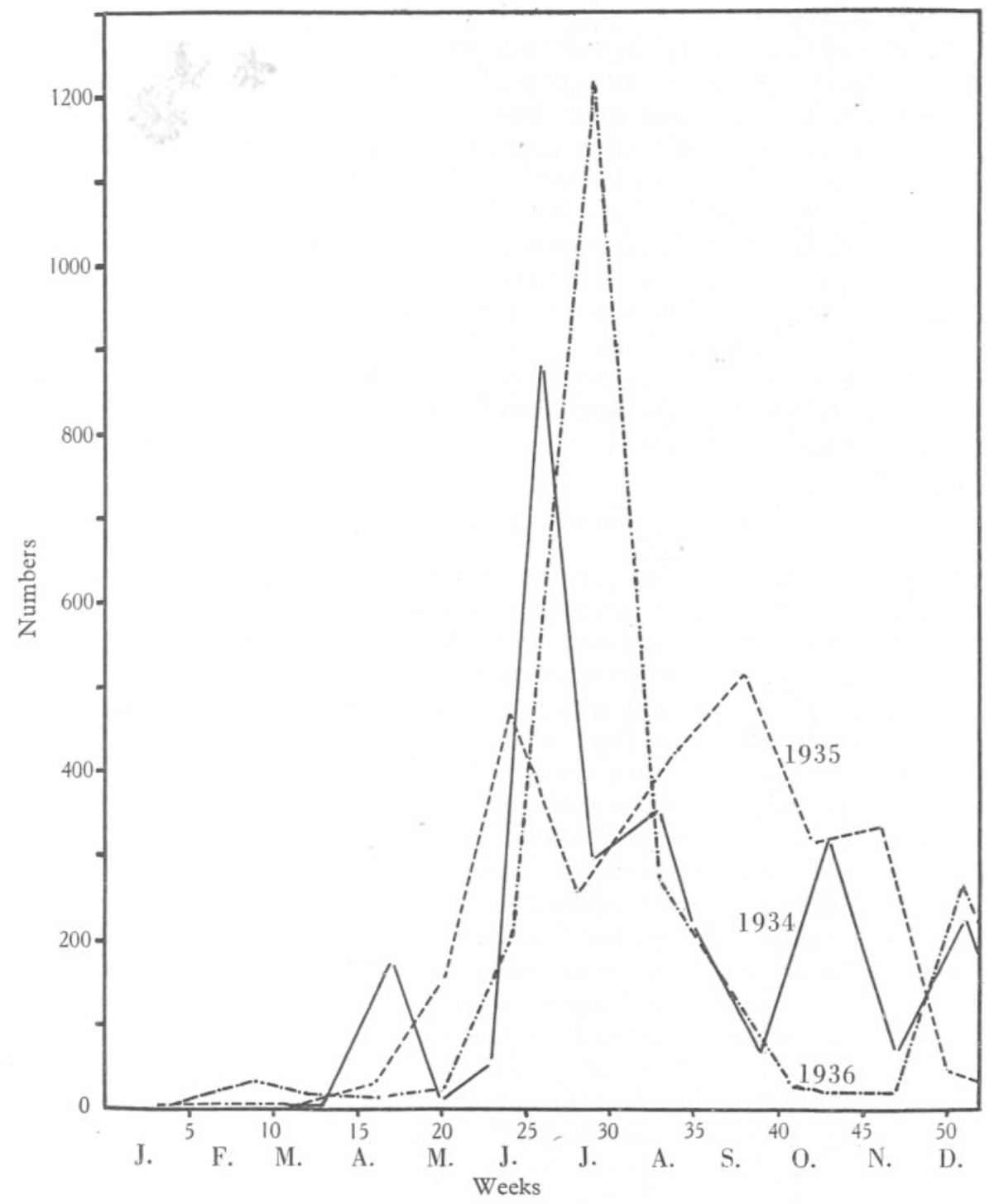

Fig. 4. Curves showing the annual change in numbers of Idotea viridis (all sizes) in roo cu. $\mathrm{m}$. of water, from New England Creek, Essex, for the years 1934, I935 and 1936, in which the totals were 2656,2339 and 3127 respectively. ( $1934 ;---1935 ;-\cdots-1936$.) 
total number of I. viridis in New England Creek was of the order of two and a quarter million.

All the idoteids collected in 1936 were measured and have been segregated into size groups, which do not represent instars. These results are shown in Fig. 5. It will be seen that newly hatched individuals (I.50-I.99 $\mathrm{mm}$. long) first appear in May, reach their maximum in July, disappear in October and November and reappear in small numbers in December, suggesting that I. viridis has a second late brood, as do many marine plankton forms; the figure also shows that animals between 2.00 and $5.99 \mathrm{~mm}$. in length represent the greater part of the plankton collections. This is taken to mean that there is a considerable mortality of young forms, especially at that ecdysis which precedes sexual maturity (Table I) and possibly that the older forms tend to some extent to remain nearer the bottom. For the reasons presented above, it is not considered that this latter factor involves any fundamental alteration in the data presented in Fig. 4 .

\section{Number of Young IN BRood Pouch}

In order to determine the fertility of $I$. viridis, the numbers of embryos in the brood pouches were counted. Preliminary investigation showed that if ovigerous females were selected as such from a collection, there was always a tendency to choose those containing large numbers of eggs, hence every female collected in I935 and I936 has been examined and, if ovigerous, the embryos have been removed from the brood pouch and counted. The embryos have been divided into three groups, (a) the spherical or semi-spherical, referred to as "eggs", $(b)$ those shaped as an oblate spheroid and with obvious mesodermal bands, "medium", and (c) those with appendages, "advanced". The results of counts made on I2I ovigerous females are shown in Fig. 6.

It would clearly be most misleading to express these results in terms of an average number of eggs per female, since there is a large number (4I) of females whose brood-pouch contained I-6 embryos, mostly in the "advanced" stage, and the remaining females fall, with six exceptions, into four main groups, containing round about $9, \mathrm{I}_{3}, \mathrm{I} 7$ and 23 embryos respectively. The exceptional animals had 26, 3I, 33, 34 and 46 embryos. There is some tendency for the "advanced" stages to be grouped on the left, i.e. for there to be few animals of this stage in the brood-pouch and for the "eggs" to be on the right. The data available do not justify an attempt fully to explain these facts, but they may be partially accounted for. Observations show that there is some difference in the stage of development of embryos within the marsupium, e.g. while the majority are ready to hatch, three or four may be at an earlier stage. It is possible that these latter may be retained after the others have left the pouch, in this way accounting for the females with 2-6 embryos. Jancke (1924) showed that in Asellus aquaticus, the number of fertilized eggs was twice reduced by expulsion, first, of early embryos and later, of more 


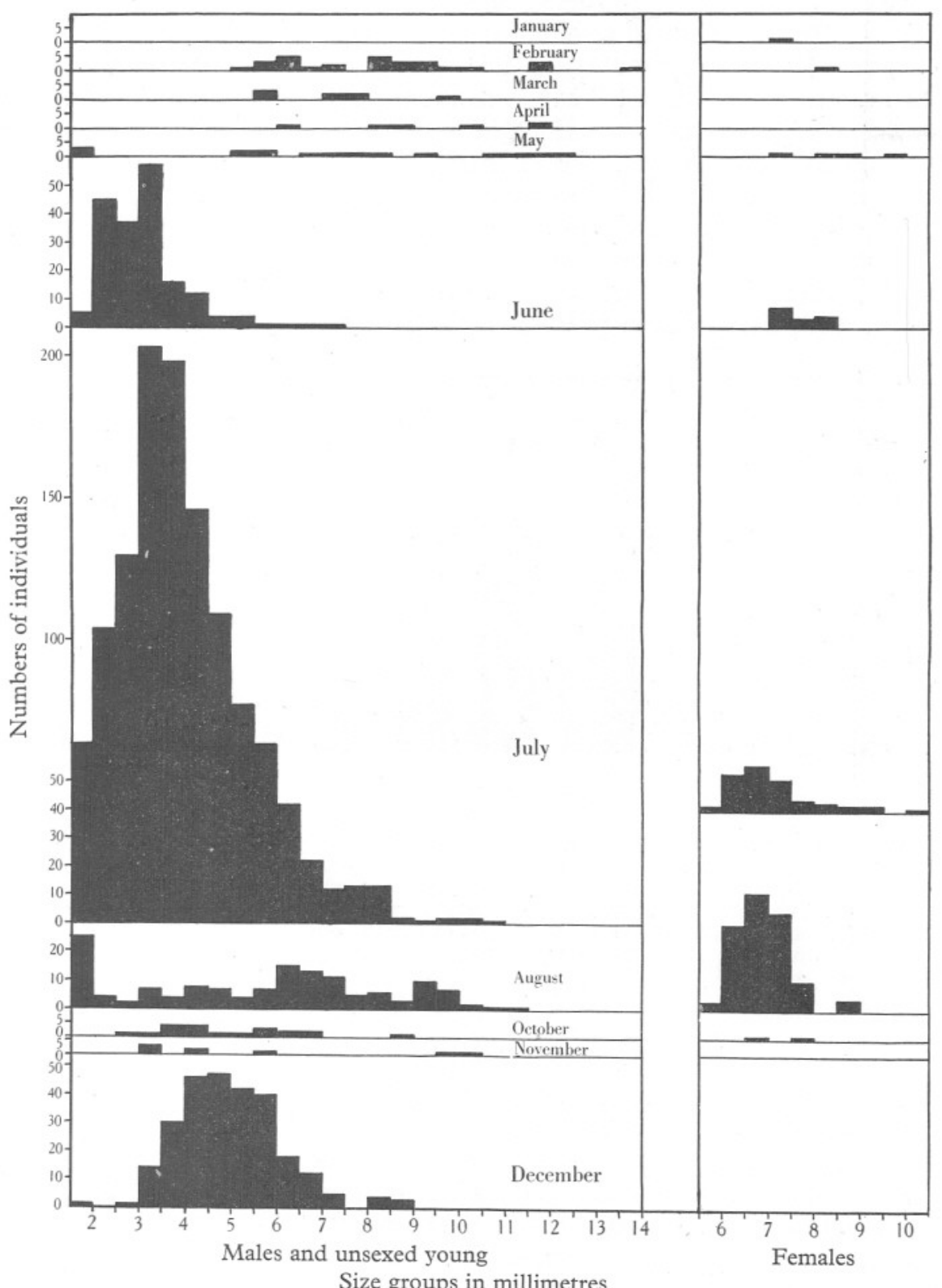

Fig. 5. Size-composition of plankton catches of Idotea viridis in New England Creek throughout 1936. 
developed embryos; 150 fertilized eggs eventually giving rise to a brood of about 8 . He also observed a similar phenomenon in Idotea viridis, according to Zimmer (1927), viz. a reduction of 30-40 eggs to $4-6$ young ready to hatch. The decrease in "advanced" and "medium" embryos from left to right in the figure suggests the possibility that a similar process also takes place in I. viridis in New England Creek. Females with only one embryo in the marsupium occurred only in August and September; it is not known whether this is again part of the phenomenon discussed above, or whether the embryo was retained in the pouch, there to pass the winter. The grouping of the remaining females is not correlated either with size of mother or with the season: it is possible that a genetical factor may be operating.

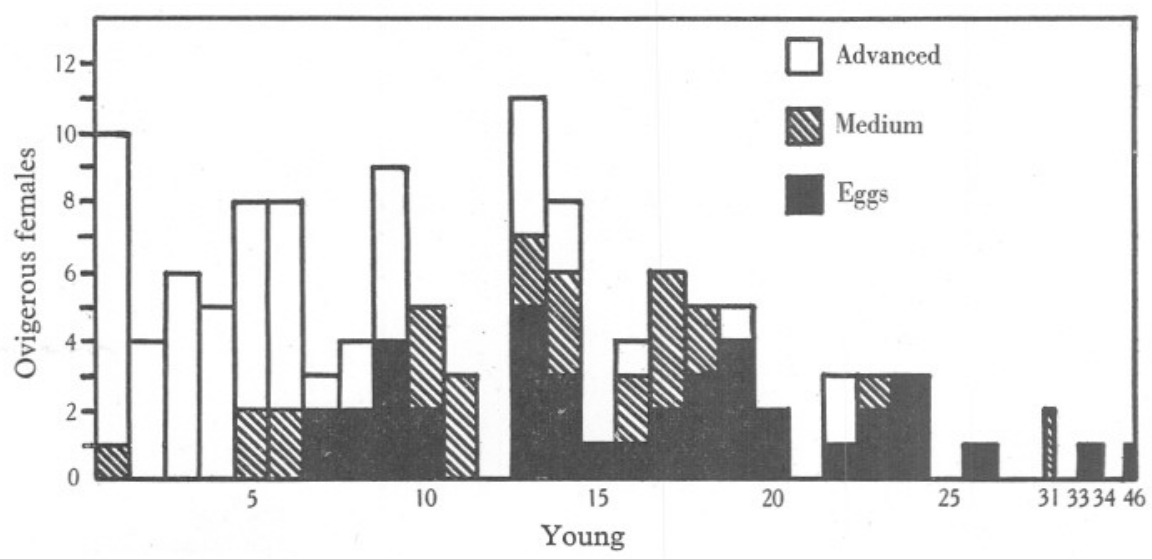

Fig. 6. Diagram showing variation in number of young in brood pouch of ovigerous Idotea viridis. The base line is divided into number of young in brood pouch and the values of the ordinates are proportional to the number of females containing a given number of eggs. The young are grouped into "eggs", "medium" and "advanced". The four columns on the right, which are half the width of the other columns, represent animals with exceptionally large numbers of young in the brood pouch. The total number of females was I2I.

\section{The Newly Hatched IDOTEA VIRIDIS}

The material upon which this description is based was collected in the plankton, but the fact that these really were newly hatched animals was confirmed by examination of young from brood-pouches.

I. viridis, when just hatched (Fig. $7 a$ ), is between $\mathrm{I} \cdot 5$ and $2.4 \mathrm{~mm}$. long, mean length I. $8 \mathrm{~mm}$. Cephalon relatively enormous, body tapering posteriorly. Flagellum of antennule consisting of two segments. Thorax of six large segments each bearing a pair of legs and one limbless posterior small segment; this is characteristic of all isopod young at this stage (Calman, 1909). Coxal plates relatively broad, visible on all thoracic segments including first and rudimentary seventh; convex laterally, large and very conspicuous on thoracic 


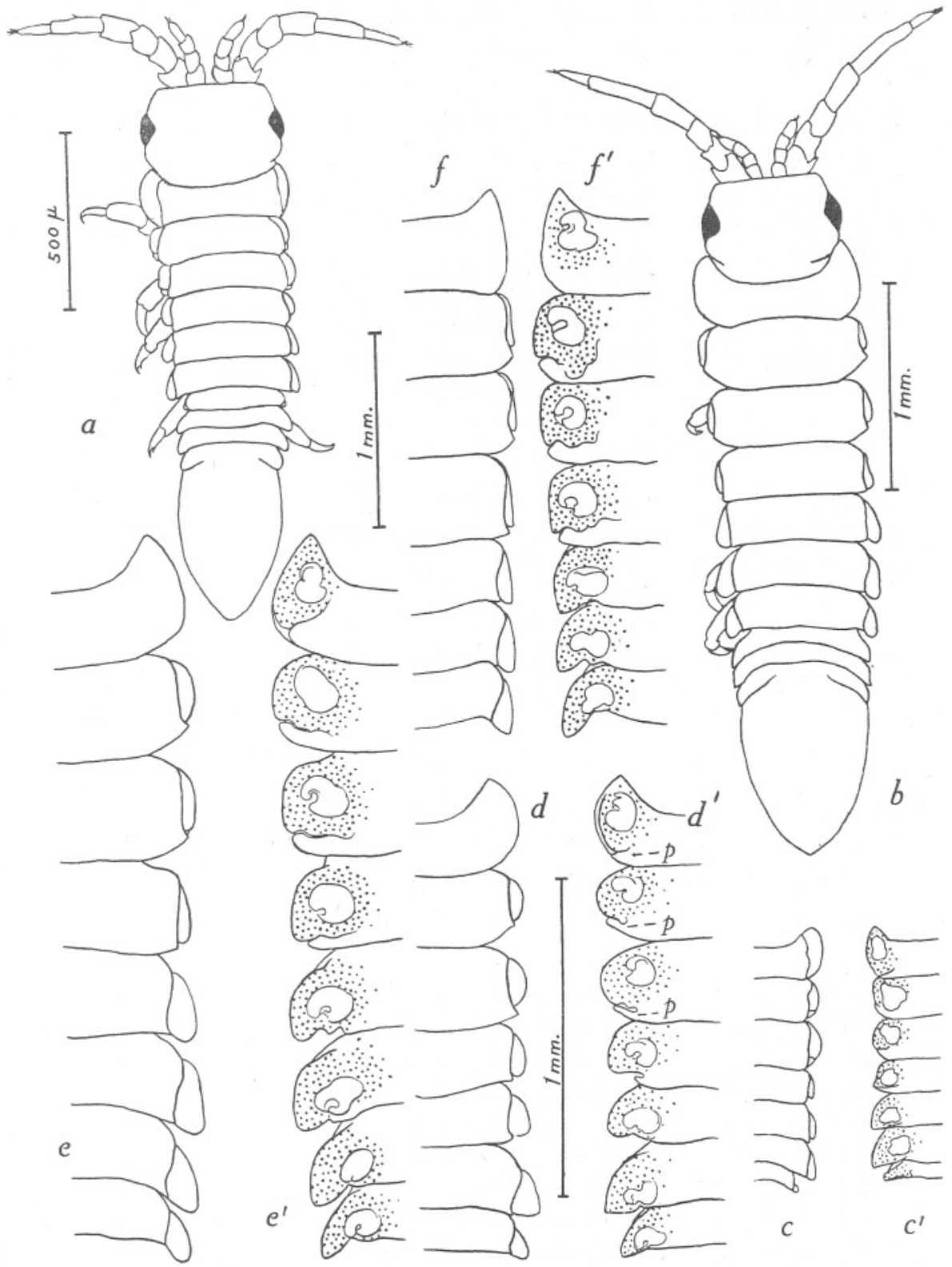

Fig. 7. $a$, newly hatched Idotea viridis; $b, I$. viridis in instar II; $c, c^{\prime}, d, d^{\prime}, e, e^{\prime}$, dorsal and ventral views respectively of coxal plates in instars I, II and III (all drawn to the same scale); $f, f^{\prime}$, dorsal and ventral views of coxal plates of instar IV; $p$, pleuron. 
segment one, diminishing in size to segment six, minute on segment seven. Abdomen with two short segments and antero-transverse groove indicating coalesced third, as in adult.

\section{The Ecdyses Between Hatching and Maturity}

Several attempt at rearing $I$. viridis from New England Creek in the laboratory were made, but, although adults lived for some weeks in captivity, they all died without growing or producing young, probably because it was impossible to maintain supplies of suitable food. Hence it was necessary to try to determine the number of ecdyses from the preserved material. It was found that if the animals were classified according to the number of joints of the flagellum of the antenna, there was marked correlation between this quantity and the length of the animal, but with considerable overlapping

\section{TABLE I. INSTARS OF I. VIRIDIS}

\begin{tabular}{|c|c|c|c|c|c|}
\hline $\begin{array}{l}\text { Ratio of mean lengths } \\
\text { of animals in instar } \\
\text { to that of animals } \\
\text { in preceding instar } \\
\text { "Przibram quotient" }\end{array}$ & $\begin{array}{c}\text { Instar } \\
\text { no. } \\
\text { I }\end{array}$ & $\begin{array}{c}\text { Number of } \\
\text { segments } \\
\text { in flagellum } \\
\text { of antenna } \\
2\end{array}$ & $\begin{array}{l}\text { Mean } \\
\text { length of } \\
\text { animals } \\
\text { in instar } \\
\text { mm. } \\
\mathrm{I} \cdot 8\end{array}$ & $\begin{array}{c}\text { Limits of } \\
\text { length of } \\
\text { animals } \\
\text { in instar } \\
\mathrm{mm} \text {. } \\
\text { I. } 5-2 \cdot 4\end{array}$ & $\begin{array}{c}\text { Notes } \\
\text { Newly hatched }\end{array}$ \\
\hline I. 44 & 2 & 2 & $2 \cdot 6$ & $2 \cdot 1-3 \cdot 6$ & \\
\hline I. 38 & 3 & 3 & $3 \cdot 6$ & $3 \cdot 0-4 \cdot 5$ & \\
\hline I. 25 & 4 & 4 or 5 & $4 \cdot 5$ & $3 \cdot 8-5 \cdot 6$ & \\
\hline$I \cdot 3 I$ & 5 & 6 or 7 & 5.9 & $4 \cdot 9-7 \cdot 5$ & $\begin{array}{l}\text { At this stage some } \\
\text { of } \text { become mature }\end{array}$ \\
\hline I. 26 & 6 & 8,9 or ro & $7 \cdot 4$ & $6 \cdot I-8 \cdot 5$ & $\begin{array}{l}\text { At this stage rest } \\
\text { of } \text {, }+ \text { become } \\
\text { mature, } \widehat{o}^{\hat{0}} \text { have } \\
\text { appendix mascu- } \\
\text { linus }\end{array}$ \\
\hline I.36 & 7 & $\begin{array}{l}\mathrm{II}, \mathrm{I} 2 \\
\text { or } \mathrm{I}_{3}\end{array}$ & IO.I & $8 \cdot 4-12 \cdot 7$ & $\begin{array}{l}\text { Males show sud- } \\
\text { den widening of } \\
\text { 6th thoracic seg- } \\
\text { ment }\end{array}$ \\
\hline
\end{tabular}

in size between adjacent classes and, in certain cases, e.g. forms with eight, nine and ten joints, almost complete overlap. Where the length of a number of animals extended over the same range, even if there were differences in the number of joints of the flagellum, they were taken as one class. It was then found that these classes could be arranged serially so that each group represented a different instar, saving that the first group included animals covering an exceptionally wide size range and with obvious morphological differences. This group will be dealt with later. That the other groups did, in fact, represent instars, was confirmed as follows: all the animals in a group were examined and those about to moult, i.e. with the skeleton of the coming instar visible inside the existing skeleton, were segregated. The new antennae could be seen inside the old antennae of these forms and hence the coming 
change in the number of joints determined; it was found that the smallest animals in group one, which had only six thoracic peraeopods, could have the same number (two) of segments in the flagellum in the following, as in the present, instar. This group was therefore separated into instars on the basis of the number of thoracic legs. It could be seen that animals of the

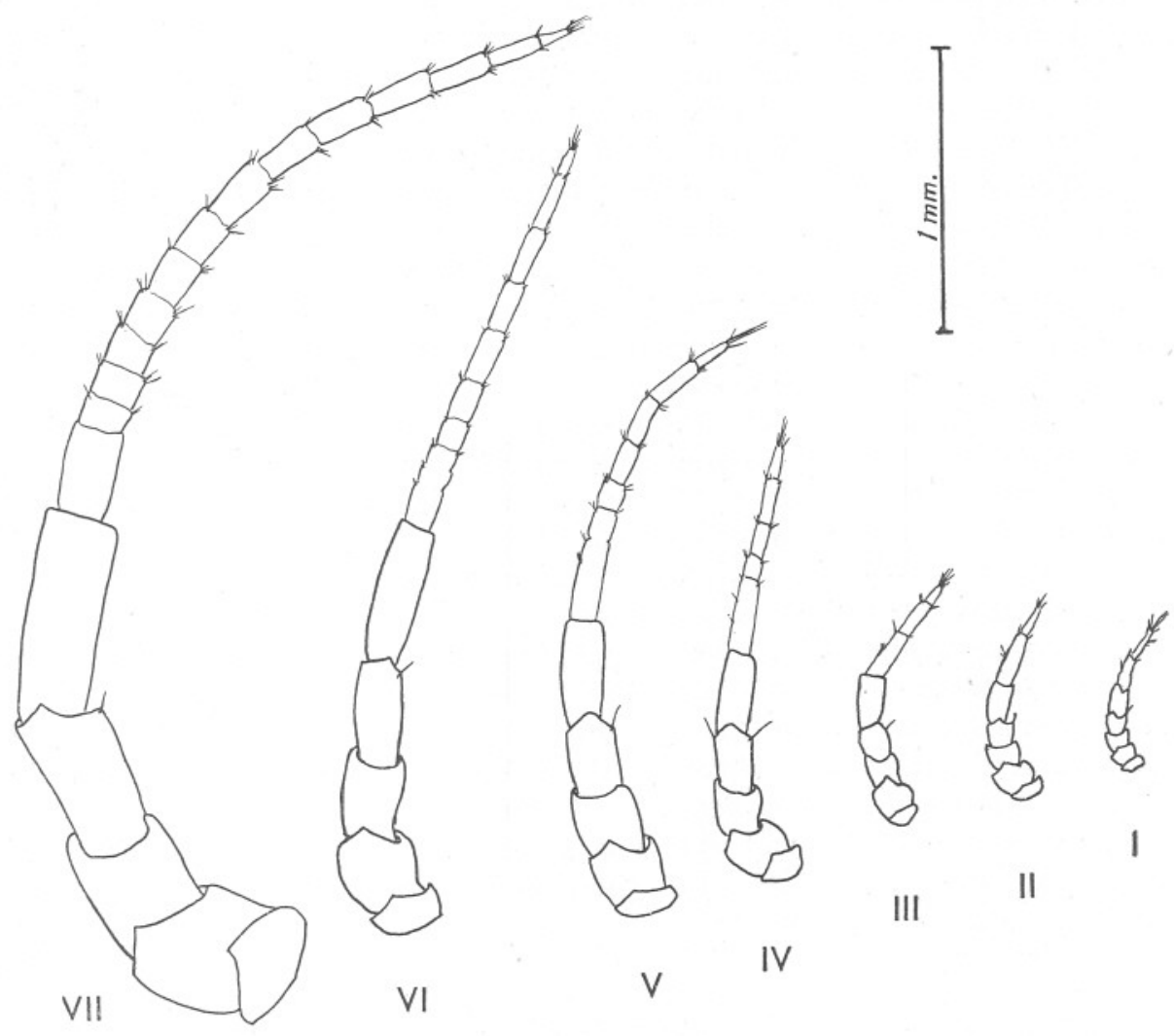

Fig. 8. Antennae of different instars of Idotea viridis showing increase in number of joints of flagellum. Newly hatched animal on right. The numbers below the appendages indicate the instar to which the animal belongs.

second instar added one joint to the flagellum; of the third, one or two; fourth, one or two; fifth and sixth, two or three (Fig. 8): on this basis Table I was constructed.

The lengths of twenty animals in each instar were measured; results so obtained are given in the table.

Normally there are six moults after hatching before the male $I$. viridis from New England Creek stops growing, and rarely there may be a seventh, after which the animal has fourteen or fifteen joints on the flagellum of the 
antenna and reaches a length of nearly $\mathrm{I} 4 \mathrm{~mm}$. Animals of this size were extremely rare. Usually, in the sixth instar the male has the appendix masculinus of the 2nd pleopod in the adult condition; females appear to become ovigerous in the fifth instar but, in any sample, females in this and the sixth instar occur in approximately equal numbers. The evidence suggests that the females moult with increase in size once after attaining maturity, but the possibility of females becoming mature in either the fifth or the sixth instar is not completely excluded. Only one female having the number of joints of the flagellum of the antenna corresponding to that in the seventh instar of the male has been found, although several hundred females have been examined. It is therefore concluded that if the females moult before each brood, as in the majority of isopods, female $I$. viridis from New England Creek usually do not change their bodily dimensions after the sixth instar. It seems unlikely that females would use the same brood pouch for successive clusters of eggs, especially since moulting is so commonly bound up with the opening of the vagina and hence with fertilization. No females with torn marsupia were ever found although in many the brood pouch was quite empty. Probably the females retire to the depths of the creek to moult. Alternatively, the females may have but one or two broods and then die. The data available do not permit of a decision being made on these points.

The fact that the great majority of the females never grow after reaching the sixth instar, while the males undergo a further moult, explains why the male of a copulating pair is always larger than his mate.

The "Przibram quotient", i.e. the ratio between the length of an animal at a given instar and that at the preceding instar, has been calculated. According to Przibram's (193I) theory, arthropods double in weight from instar to instar and hence, assuming that the body does not alter in form, the corresponding ratio for increase in length should be $\sqrt[3]{2}$, i.e. I.26. The figures given suggest that this "law of geometrical progression" may be applicable to the growth of $I$. viridis.

\section{Changes IN Bodily Form}

The post-embryonic changes in bodily form and in the shape of some of the appendages of $I$. viridis have been investigated. There is considerable change both in the shape and proportions of different parts from instar to instar and, in this paper, only those parts showing the most marked and what are believed to be taxonomically the most significant changes, are dealt with. These changes are described in two ways: $(a)$ where no irregular alteration in shape is involved, a series of measurements has been made and plotted on a double logarithmic grid to test for simple allometry (Huxley \& Teissier, 1936); (b) where changes in shape not easily susceptible to measurement, or in number of joints, etc. do occur, e.g. uropods or antennae, these have been illustrated serially in Figs. 7, 8 and $I_{3}$ and are described in the text. 


\section{Allometry}

Measurements were made on I4I unsexed and male $I$. viridis and on 45 females. Females were only distinguished from the fifth instar onwards. The dimensions selected for discussion are illustrated in Fig. 9; actually many more dimensions were measured, but, since the object was primarily to facilitate the description of morphological changes rather than to discuss "relative growth", they have been omitted.

The dimensions taken (Fig. 9) are, the greatest breadth of the cephalon and of the third and sixth thoracic segments, including the coxal plates, the length of the seventh thoracic segment and the length of the abdomen: the first three are compared with the total length as the standard, measured from a line drawn transversely between the tips of the anterolateral projections of the cephalon to the posterior tip of the abdomen, the fourth with the total length minus the length of the seventh thoracic segment, and the fifth with the length of cephalon plus thorax only. "The law of simple allometry can be expressed by a formula of the type, $y=b x^{\alpha}$, where $y$ is the part, $x$ the standard or whole, and $b$ and $\alpha$ are constants" (Huxley \& Teissier 1936, p. 780) so that if simple allometry is acting, the graph of $\log y / \log x$, is a straight line (Huxley, 1932).

In this paper, the three standard dimensions described above are taken as $x$ and the other five as the compared dimension $y$.

The best fitting line to the plot of the logarithms of $x$ and $y$ has been calculated from the logarithms of the measurements by the method of least squares. No attempt has been made to group the data since it was

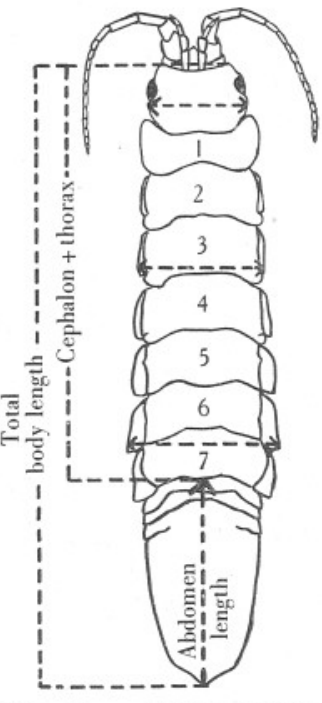

Fig. 9. Idotea viridis. Dimensions employed in discussion on allometry. difficult to decide upon a suitable basis of classification. Grouping according to size would cause animals from different instars to be placed in the same class and grouping in instars seemed unwise owing to the considerable overlap between adjacent instars (Table I). The values obtained for $\alpha$, the equilibrium constant or growth constant (Huxley \& Teissier, I936) only are given since the constant $b$ depends on the units of measurement employed and has been altered in the graphs (Figs. IO, II), to avoid superimposing them. In the animals examined, the body length ranged from $\mathrm{r} \cdot 6$ to $13 \cdot 4 \mathrm{~mm}$.

The graphs of $\log y / \log x$ (Figs. IO, II) do appear to fall reasonably well on a straight line and it is therefore concluded that simple allometry is at work and that the "growth constant" $\alpha$ may justifiably be calculated from the data. 
Sixth thoracic segment (Fig. IOB).

In adult males the body is at its broadest in the region of the fifth and sixth thoracic segment, which rarely differ significantly in breadth. The "growth

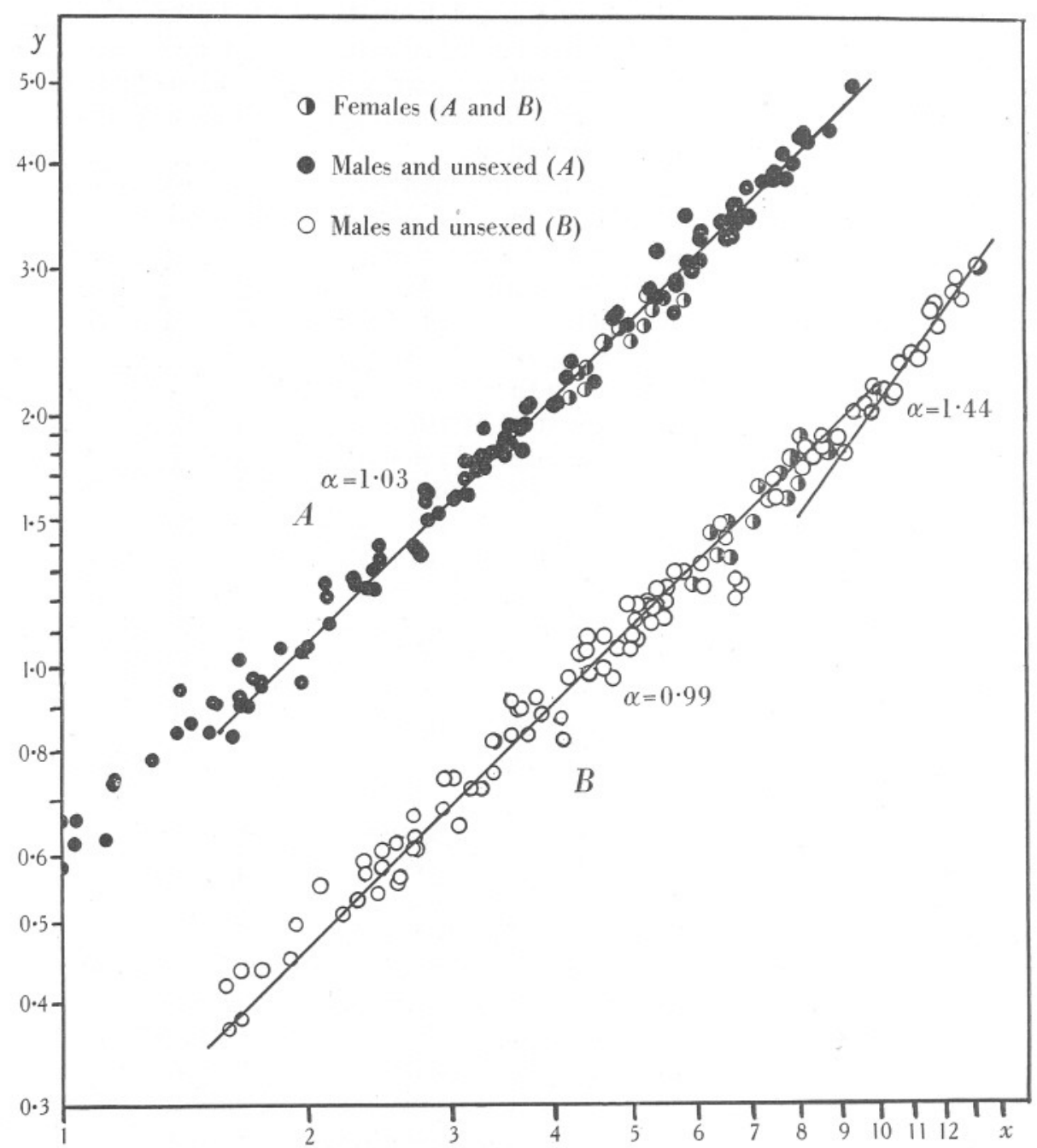

Fig. Io. A (upper line); length in millimetres of abdomen $(y)$ plotted against length of cephalon + thorax $(x)$. B (lower line); breadth in millimetres of 6 th thoracic segment $(y)$ plotted against total body length $(x)$. Both double logarithmic plots.

constant" of the breadth of this segment, body length being used for comparison, therefore gives valuable information as to whether the animal as a whole becomes slimmer or broader during growth: further it is chosen in 
preference to the fifth segment because, in the females, it is less likely to be influenced by the broadening of the more anterior segments concomitant with the formation of a marsupium. It is to be doubted whether the value of $\alpha, 0.994$, differs significantly from I, so that up to and including the sixth instar, the sixth thoracic segment in the unsexed animals and in males and females grows isometrically with the body length and the overall bodily dimensions are unaltered. In the seventh instar the body becomes stouter, since the constant is now $\mathrm{I} \cdot 44$. It is interesting that the sixth thoracic segment in the female behaves as that of the male and is uninfluenced by the formation of the brood pouch.

\section{TABLE II. VALUES OF $\alpha$}

\begin{abstract}
$x$
Total body length

Total body length

Total body length

Total body length minus length of 7 th thoracic segment

Length of cephalon plus thorax
\end{abstract}

\begin{tabular}{ccl}
$y$ & $\alpha$ & \\
Cephalon breadth & 0.83 & \multicolumn{1}{c}{ Notes } \\
Breadth of 6th & $1 \cdot 44$ & Instar VII \\
thoracic segment & 0.99 & Instars I-VI inclusive \\
Breadth of 3rd & 0.88 & Males and unsexed \\
thoracic segment & $2.4 \mathrm{I}$ & Females, instars V? and VI \\
Length of 7th & $2 \cdot 03$ & Instar VII \\
thoracic segment & I.I5 & Instars III-VI inclusive \\
& irregular & Instars I and II \\
Length of abdomen & & Instars II-VII \\
& & Animals in instar I appear \\
& & to deviate from line
\end{tabular}

Third thoracic segment (Fig. II A).

The third thoracic segment is the widest in the adult female. The widening appears to take place at the ecdyses between the fourth and fifth, and fifth and sixth instars, and if the line is produced back to meet that for unsexed animals and males, it cuts the latter at a point equivalent to a body length of $6.3 \mathrm{~mm}$. This is fairly close to the mean length $(5.9 \mathrm{~mm}$., with a range of from 4.9 to $7.5 \mathrm{~mm}$.) of animals in the fifth instar, and suggests a sudden rather than a gradual response to the developing gonads. The "growth constant" (0.88) of this segment for unsexed animals and for males shows that it becomes proportionately narrower with increasing age, so that the widest region of the thorax moves back to the sixth thoracic segment.

\section{Seventh thoracic segment.}

The seventh thoracic segment of the newly hatched animal is very small: at the first moult it doubles in length and then thereafter up to and including the sixth instar has a growth constant of I.I5 compared with the total length minus the seventh thoracic segment. In the seventh instar the constant rises to 2.03 . 


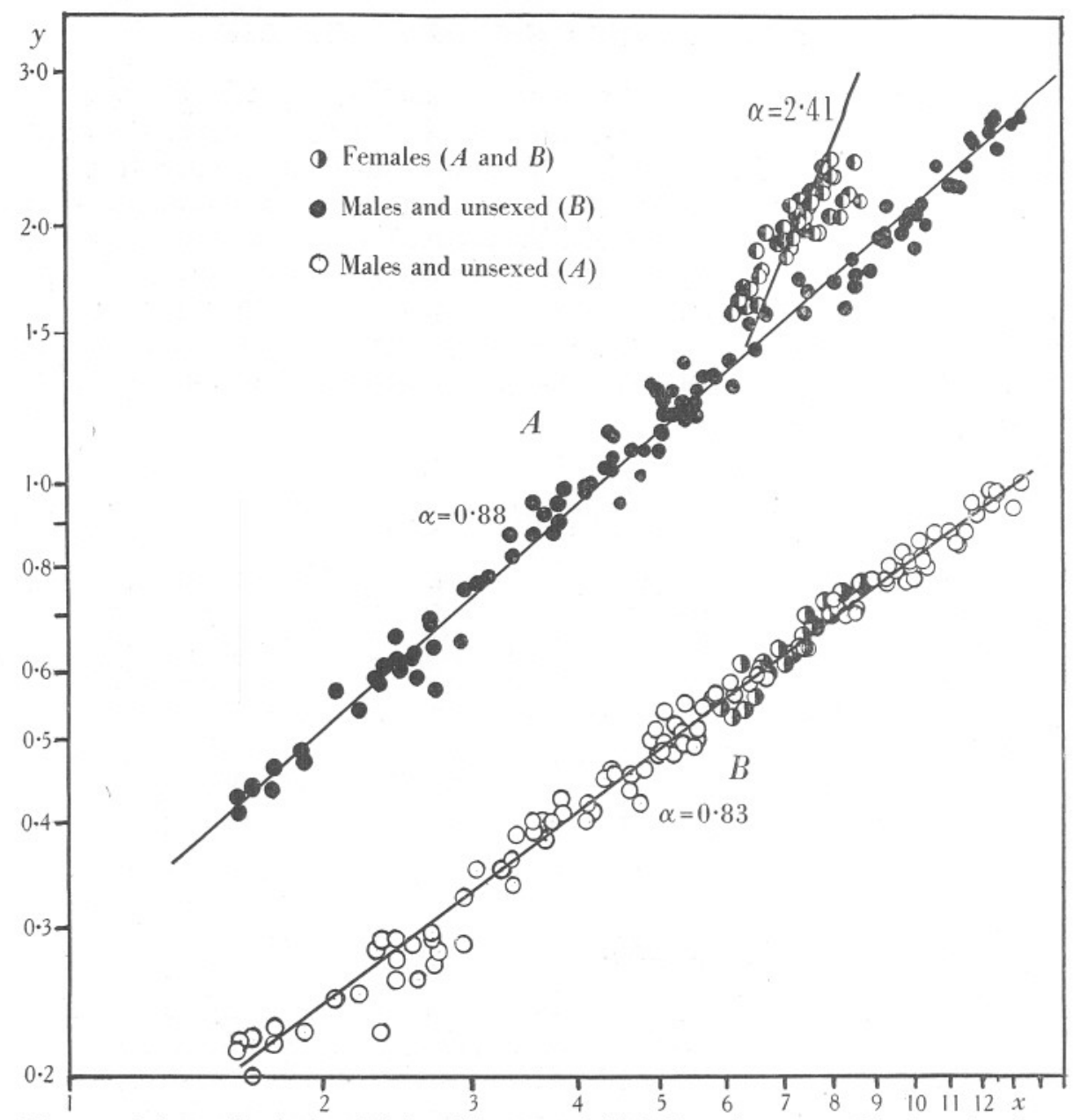

Fig. II. A (upper line); breadth in millimetres of third thoracic segment $(y)$ plotted against total body length $(x)$. B (lower line); breadth of cephalon $/ 2(y)$ plotted against total body length $(x)$. Both double logarithmic plots.

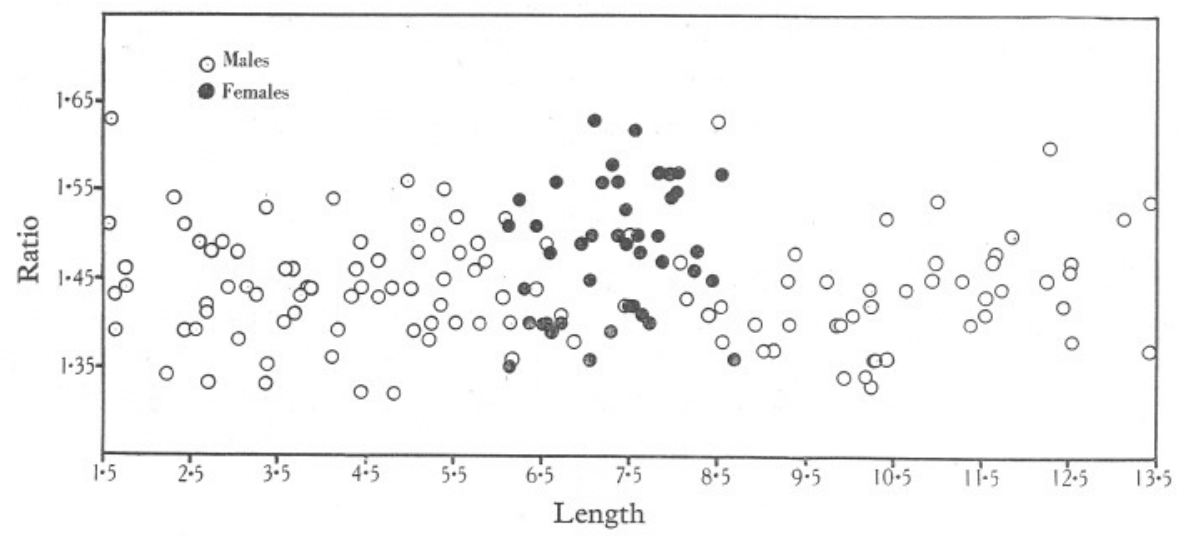

Fig. I2. Ratio cephalon breadth/cephalon length of individual animals plotted against total body length (anterior border of cephalon to posterior tip of animal) in millimetres, showing that the ratio does not change as the animal becomes bigger. 
Cephalon (Figs. I I B, I2).

The cephalon becomes proportionately narrower and shorter with age compared with the rest of the body but the ratio length/breadth of its overall dimensions does not change although its anterior margin becomes convex anteriorly and there is some change in outline. The relatively enormous cephalon of the newly hatched Idotea is shown in Fig. 7 a.

Abdomen (Figs. ro A, 13).

The proportion of abdomen to thorax plus cephalon does not change significantly after the second ecdysis. There is some evidence from the graph that in the first two instars the growth constant is less than I and while both the number of points and their wide scatter make it difficult to come to any definite conclusion, it is clear that this is correlated with the doubling in length of the seventh thoracic segment during the first post-embryonic moult. Following this, the abdomen grows isometrically with the cephalon plus thorax. Since this is so, and since the growth constant of the cephalon is 0.83 , it follows that the thorax (morphologically the second to eighth thoracic segments) occupies an increasing proportion of the total length as the animal becomes older. The ratio breadth/length of the abdomen remains constant at approximately $I \cdot 9$ throughout the whole post-embryonic period, hence the same growth constant is applicable to its breadth as to its length.

\section{CHANGES IN SHAPE}

Seventh thoracic segment (Fig. $7 c, d, e, f$; Table II).

I. viridis is hatched with a small, limbless seventh thoracic segment, as is usual in isopods. In instar II this segment becomes proportionately larger in all dimensions, doubling in length, although the total length of the animal is only I.44 times as long as in instar I, and short limbs are present. It continues to grow at a rapid rate, increasing in size proportionately to the other segments at each instar until in instar $\mathrm{V}$ it is only a very little shorter than the longest thoracic segment. In the last instar it again shows a sudden proportionate increase in length.

\section{Coxal plates (Fig. $7 c, c^{\prime}, d, d^{\prime}, e, e^{\prime}, f, f^{\prime}$ ).}

As has been stated above, $I$. viridis is hatched with exceptionally large coxal plates (Fig. $7 a, c, c^{\prime}$ ) and it is especially noteworthy that not only do they occur on the six posterior thoracic segments but that they are large and conspicuous on the first. In the second instar, the coxal plates of segment one are no longer visible from the dorsal surface but their lateral boundaries can still be seen on the ventral surface (Fig. $7 d^{\prime}$ ). It is believed that they are still present in all later instars but fuse with the ventral side of the segment 
(Fig. $7 e^{\prime}, f^{\prime}$, shaded area on first thoracic segment). The lateral expansions of the first thoracic segment would therefore be the pleura of that segment which have not been replaced by the coxal plates (Calman, I909, p. 202). Clearly it is impossible to follow the behaviour of these coxal plates without histological examination. The coxal plates on thoracic segments two, three and four of animals of instar I are comparatively large; in the second instar they have increased proportionately in size and have become very convex laterally, but do not occupy the whole of the lateral margin of the segment (Fig. $7 d$ ). The pleura are small (Fig. $7 d^{\prime}$ ). In instar III (Fig. $7 e, e^{\prime}$ ) the coxal plates have become flattened and have diminished in size relative to their segments and the pleura have grown out laterally behind them. In instar IV (Fig. $7 f, f^{\prime}$ ) the coxal plates have become more flattened, have extended to the anterior border of the segment, and the pleura are now flush with their outer borders. This is the adult condition and no further changes of any magnitude occur. The whole process can be summarized as initial growth of the coxal plates followed by a change in shape accompanied or possibly induced by later growth of the pleura. On segments five, six and seven the same process occurs except that there is no late growth of the pleura.

\section{Antennule.}

The changes in shape of the antennule of the successive instars are illustrated in Fig. I3 $a$, I-VII. Apart from the gradual assumption of the adult form, the most obvious changes are in the flagellum. In instars I and II this latter is conical and bears only one aesthetasc. In instars III, IV, V and VI it becomes first of all cylindrical and then rounded at its antero-medial border; at the same time the number of aesthetascs increases from 2 to 3,3 to 4 and 4 to 6 respectively. In the last instar the antero-medial margin becomes sloped and there are eight aesthetascs arranged in a series along the slope. The change in shape of the flagellum along its antero-medial border appears to be due largely to the increase in the number of aesthetascs. Round the base of each of these the exoskeleton appears to become flattened and hence when they cease to be confined to the tip of the flagellum and spread along its antero-medial margin, this becomes terraced.

Antenna (Fig. 8).

The changes in the number of joints of the flagellum of the antenna have already been discussed. The peduncle chiefly shows a thickening of the joints.

In the female, both antennule and antenna have the form characteristic of the sixth instar.

\section{Maxillula.}

The first maxilla possesses its characteristic number of spines from the first instar onwards but at first they may be smooth and they may not achieve the toothed condition characteristic of the adult until the fifth or sixth instar. This is variable. 


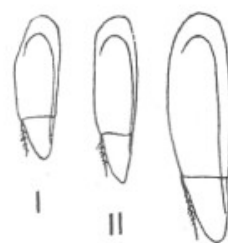

III

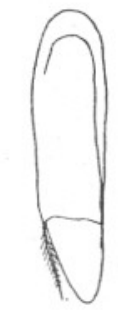

IV
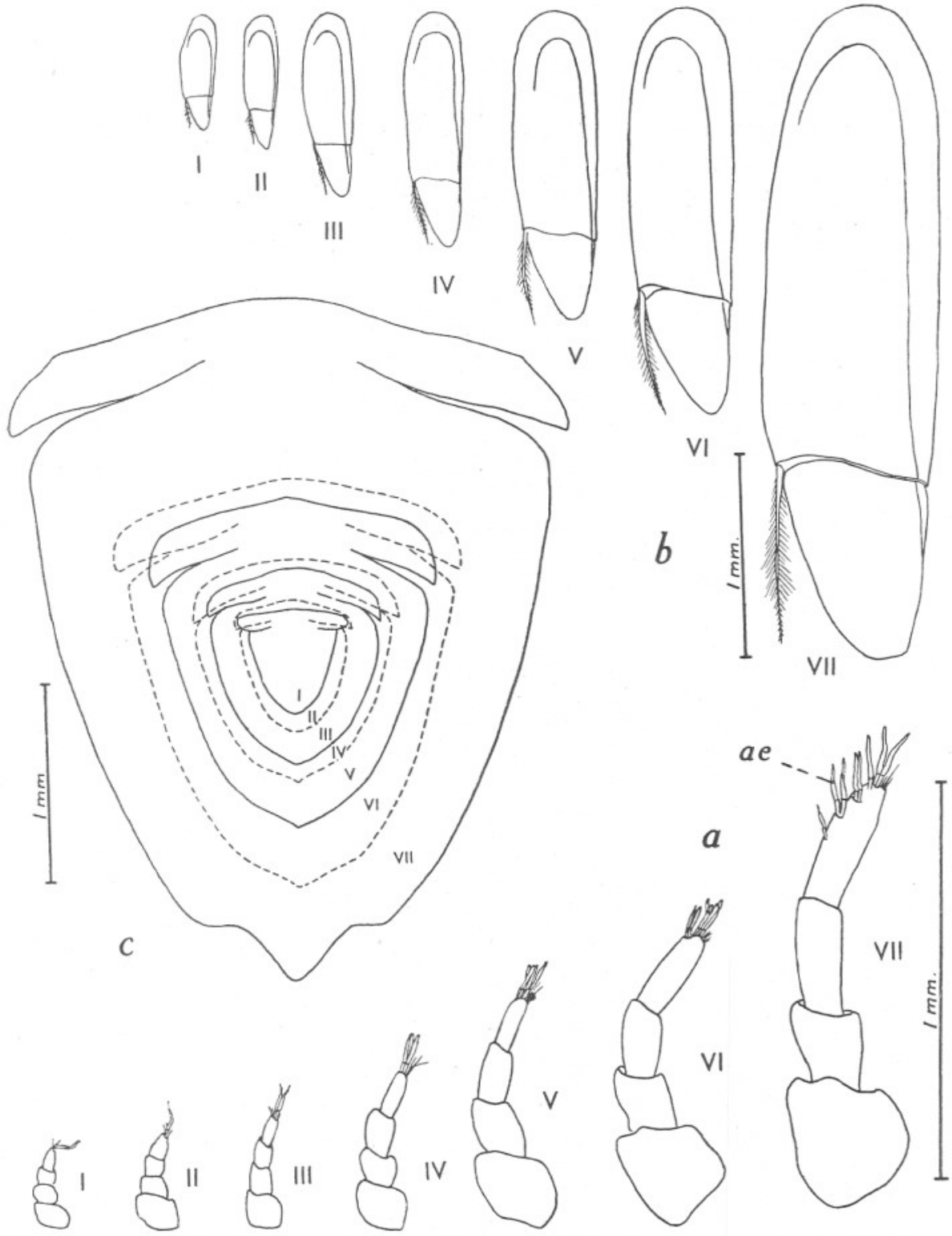

Fig. I3. a, antennule of different instars of Idotea viridis showing change in shape of flagellum and increase in number of aesthetascs $(a e) ; b$, right uropod from anatomical ventral surface (in these two cases the appendage of the newly hatched animal is on the left and the number below each appendage refers to the instar to which the animal belongs); $c$, abdomina of different instars, numbers indicating the instar, newly hatched animal in centre. The boundaries of the abdomina of alternate instars are dotted for clarity. The preparations were made by dissecting out pleopods and soft tissues and pressing abdomen flat. 
Abdomen (Fig. I3c, I-VII).

The shape of the posterior part of the abdomen varies from instar to instar, as shown in the figure. The posterior tooth appears first in the fourth instar, the postero-lateral angles in the sixth instar and only in the seventh is the characteristic adult form assumed. The shape of the exoskeleton of the female abdomen is characteristically that of the sixth instar but the arrangement of pigment and of melanophores is usually such as to emphasize the posterolateral angles.

\section{Uropods.}

Since these fold over on the ventral surface of the abdomen, forming the floor of a box enclosing the pleopods, it is to be expected that their changes in shape are correlated with those of the posterior fused segments of the abdomen. This is indeed the case (Fig. $\left.\mathrm{I}_{3} b, \mathrm{I}-\mathrm{VII}\right)$. The flattened posterior border of the uropods in instar VII is correlated with the fact that with the full development of the posterior tooth and lateral angles of the abdomen, the uropods do not form a floor on the ventral surface of the tooth, but run straight across from the transverse straight portion of the postero-lateral angles.

\section{Discussion}

The data on the biology of Idotea viridis from New England Creek have been briefly discussed above and since they are not necessarily applicable to $I$. viridis from other habitats or to the genus in general, will not be further dealt with.

Relative growth in an isopod, Asellus aquaticus, has recently been investigated in detail by Needham (1937) and it is of interest to see how far his results aid in the interpretation of the less extensive data obtained with Idotea viridis and how far the relative growth of the two animals is similar. The data given here are for post-embryonic development only and would therefore fall during Needham's "later period of simple allometry" but it seems possible that persistent rhythmic variations in $\alpha$ occur in I. viridis as also in this period in Asellus aquaticus (Figs. IO, II). The values of $\alpha$ in Idotea viridis compared with those obtained by Needham (Table II, p. 293) in Asellus aquaticus are as follows:

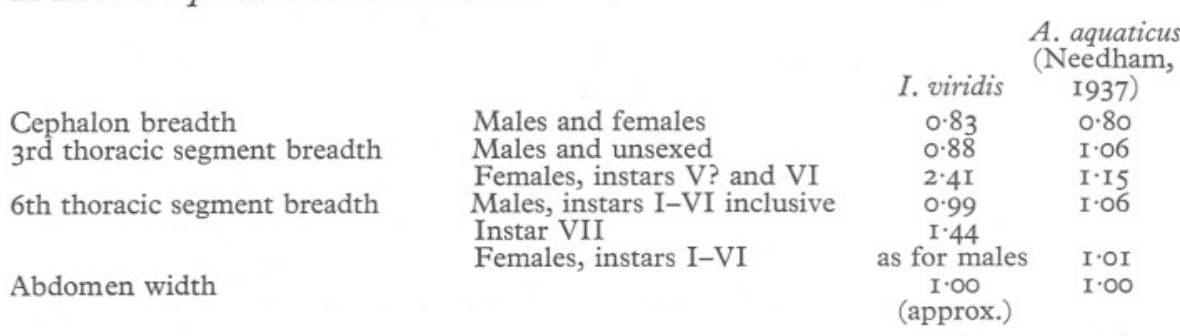


On the whole there appears to be a general similarity in the results obtained with the two animals. The cephalon (head plus morphological Ist thoracic segment) breadth is negatively allometric in both species and the values of the growth constant surprisingly close. On the other hand, Idotea viridis becomes slightly slimmer or retains nearly a constant build up to and including the sixth instar, while Asellus aquaticus becomes slightly stouter.

There is considerable evidence that the changes in regional growth rates follow the same plan in both animals. The broadest region moves back in Idotea viridis, as in Asellus aquaticus, and similarly the sixth thoracic segment becomes the broadest in adult males, while in the females the broadest region moves forward at maturity to the third thoracic segment. Needham's (1937, p. 306) discussion on the question of the occurrence of a "metamorphic moult" has important bearings on the suddenness of the change in growth rate of the third thoracic segment in the female Idotea viridis. It does appear that in $I$. viridis there is in fact a "metamorphic moult", between the fourth and fifth instars, but the number of points above the line between total body lengths of 5 and $6 \mathrm{~mm}$. (Fig. I I A) suggest that the growth centre may neither move forward so rapidly as the diagram suggests, nor may the growth constant for the third thoracic segment be so high. This appears to be in agreement with the findings of Needham, but, since this worker does not claim that his groups correspond to instars, it is difficult to find an exact parallel in the two cases. There seems to be no sign of a corresponding sudden widening of the third thoracic segment in the male I. viridis, although there is in Asellus aquaticus, and Needham's fig. 4 gives no evidence of the sudden widening of the sixth thoracic segment in the male A. aquaticus such as occurs in Idotea viridis. Sudden changes in bodily form as the gonads mature appear to be characteristic of $I$. viridis.

As in Asellus aquaticus (Needham, 1937, p. 310), the difference in shape of the sexually mature Idotea viridis is correlated with their breeding habits. The brood pouch is developed in the region of the anterior thoracic segments, hence their wideness, and similarly the relative breadth of the fifth and sixth thoracic segments in the male is probably correlated with his carrying the female underneath his body while mating.

The data on relative growth show that the form of $I$. viridis does change from instar to instar and it is therefore not to be expected that if the volume is doubled at each moult the "Przibram quotient" will equal $\mathrm{I} \cdot 26$ in every case. Table I shows that in the earliest moults when the seventh thoracic segment is increasing rapidly, the quotient exceeds $I \cdot 26$, in other words the animal lengthens in proportion to its volume; for the moults between the third and fourth, fourth and fifth, and fifth and sixth instars when other data show that there is little change in form, the quotient is very close to $\mathrm{I} \cdot 26$; while when the seventh thoracic segment again suddenly increases in length (Table II) between the sixth and seventh instar of the males, the quotient again rises. The values given in Table I, taken in conjunction with the other 
data, strongly suggest that the "law of geometrical progression" is applicable to the growth of $I$. viridis. There appear to be no similar data available for other isopods with which these results can be compared.

The changes which, while not easily lending themselves to measurement, are presumably caused by differential growth rates similar to those discussed above, are striking, especially those of the coxal plates (Fig. $\left.7 c-f^{\prime}\right)$. I. viridis is hatched with large coxal plates on all the thoracic segments, except the maxillipedal, including the anatomical first, on which they are large and conspicuous. The coxal plate on the first thoracic segment later becomes indistinguishably fused with the pleuron in the adult. As growth proceeds, the relative size of the coxal plates is reduced, partly maybe owing to the proportionate increase of soft parts relative to exoskeleton setting up mechanical stresses which tend to pull them below the pleura, but also, at any rate in segments two, three and four, by the late growth of the pleura. Since in the Asellota the coxopodite is still movably articulated with the body (Calman, I909), it might be expected that the fusion of the coxopodite with the body, and hence the formation of coxal plates, took place late in the phylogeny of the Isopoda and that the coxal plates would appear late in ontogeny. If so, apparently the evolutionary process has become reversed and, while originally lateral growth of the pleura preceded growth of the coxopodite, it now takes place the other way round.

The increase in the number of joints in either the antennule or the antenna during growth is probably of widespread occurrence in Crustacea where one of these appendages is very long. Schellenberg (1938) has recorded an increase in the number of joints of the outer flagellum of the antennule of Niphargus tatrensis var. aggtelekiensis similar to that found in the antenna of Idotea viridis. The changes in the antennule and maxillula are of the type that might be expected to occur during growth and are regular throughout. On the other hand, the abdomen and hence the uropods assume their final characters somewhat suddenly. Bate \& Westwood (I868, vol. II, p. 38I) observed the "comparative paucity of the articulations of the lower antennae in young individuals" of I. tricuspidata (now I. baltica (Pallas)) and that animals from the British Museum collection exhibited "variations in the form of the terminal segment of the body, with the length and size of the respective specimens". Again, Tattersall (I906, p. 48) in discussing I. baltica states that "Young examples of this species are difficult to distinguish from such species as $I$. pelagica, I. granulosa and $I$. viridis, in which the telson has a very similar shape". On the other hand, Collinge (1917, p. 728) states that he found very few variations in the form of the antennae, apart from the number of joints in the flagellum, or in the shape of the terminal segment of the body, and Sars (1899, p. 8I) found the terminal segment in I. baltica " to be pretty constant even in very young specimens". No data on the development of an idoteid other than those given in this paper appear to be available, but, on the grounds that positive evidence outweighs negative evidence, there is 
reason to believe that changes in shape of the abdomen occur during growth in I. baltica as they do in I. viridis, to which species the observations of Bate \& Westwood are decidedly applicable since the shape of the abdomen changes considerably during growth (Fig. I3). How far these observations can be further extended to other species remains to be seen.

Huxley lays great stress on the important bearing of allometry on taxonomy and states (1932, p. 204) "systematists are agreed that mere size differences may have no taxonomic significance... but they usually attach much greater importance to differences in the percentage size of parts. Our studies of heterogony (i.e. allometry), however, make it obvious that such differences may have precisely as little taxonomic significance as those in absolute size." If one includes under allometry all the changes observed during the postembryonic development of $I$. viridis, the relevance of Huxley's remarks is at once apparent. Collinge (I9I7, p. 737) uses body shape, width of coxal plates and shape of abdomen in his key to the British species of the genus Idotea and in this paper it has been suggested that the first and the last of these be employed as diagnostic characters of $I$. viridis: it has, however, been shown above that not one of these characters is constant throughout the whole post-embryonic life of $I$. viridis and, since little is known of the early instars of closely related forms, it may prove difficult to distinguish between them. Further, additional characters such as the shape of, and number of aesthetascs on, the flagellum of the antennule vary from instar to instar, as do the number of joints in the flagellum of the antenna. Only the ratio breadth/length of the cephalon and the number of spines on the outer lobe of the maxillula emerge as constant throughout the whole period.

It is quite easy to see that if males and females of $I$. viridis became sexually mature either one instar earlier or later than they do in New England Creek, they would differ from the New England Creek adults in general appearance or "habitus", in the proportions of many parts and in the shape of the abdomen. There is evidence that a process of this nature does occur. Adult males of $I$. viridis from different localities may vary in body length from 9 to $23 \mathrm{~mm}$., although I $2 \mathrm{~mm}$. appears to be the commonest length (Collinge, I9I7, p. 729).

The change in shape of the abdomen has been investigated in specimens from Mr Spooner's and my collections (Fig. I4); the results show that in small adult males, while the postero-lateral angles of the abdomen do appear to be considerably less marked than in larger forms, the median tooth is much less affected, although in the smaller forms ( $a$ and $b$ ) there is some tendency for the abdomen to be similar in shape to that of the fourth and fifth instars of the New England Creek form. It has proved to be possible to arrange the abdomens in series according to the development of the posterolateral angles and a comparison between Figs. I3 and I4 shows that this follows fairly closely the ontogenetic sequence. The correlation between size and shape is not very clearly marked but close correlation is not to be expected 


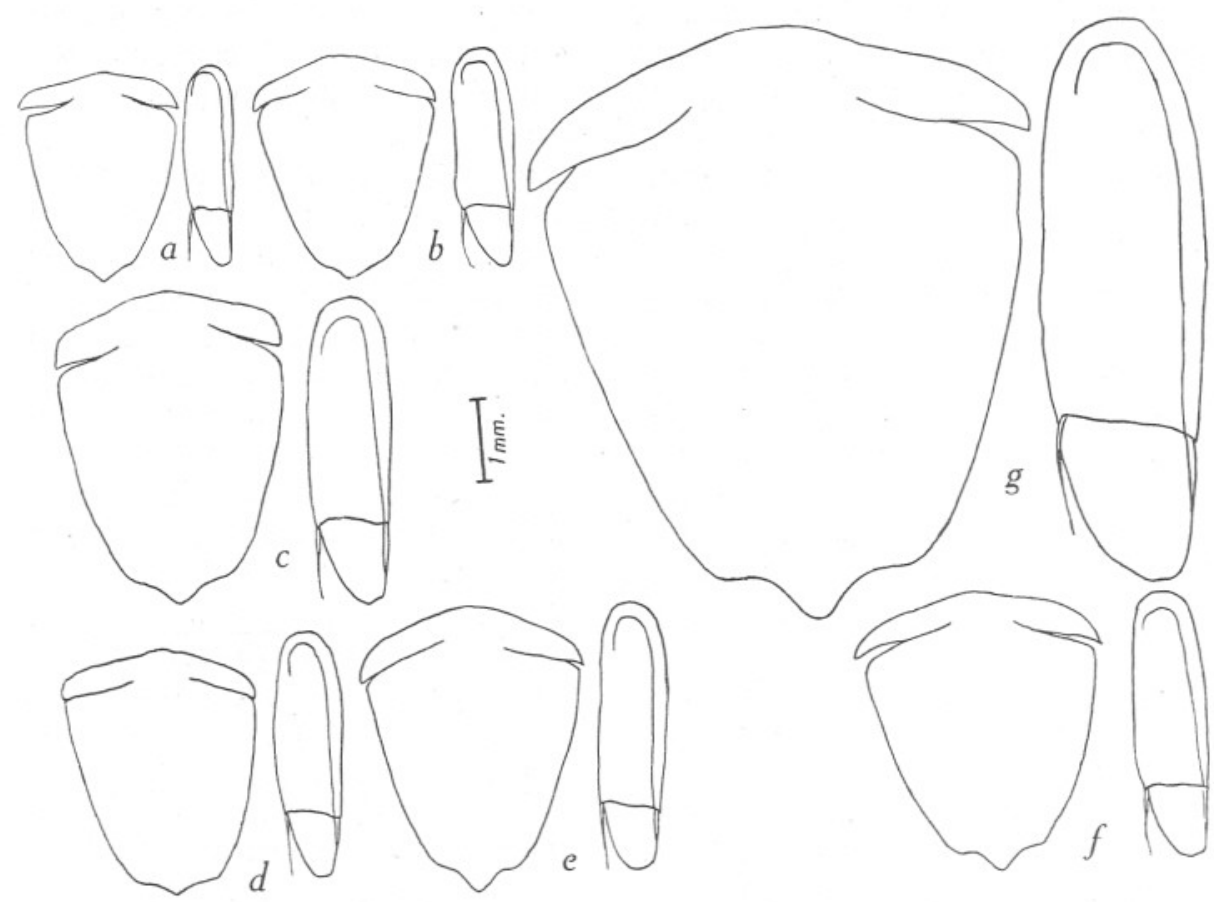

Fig. I4. Abdomens of adult male Idotea viridis from various localities arranged in series to illustrate the different degrees of development of the postero-lateral angles. Right uropods showing correlated changes in shape are included. The abdomens have been prepared by flattening after removal of pleopods and tissues. In the following table, when animals from two localities are entered under the same letter, the first only has been drawn, since the abdomens from males from both sources are similar.

\begin{tabular}{|c|}
\hline $\begin{array}{l}\text { Abdomen } \\
\text { and } \\
\text { uropod. }\end{array}$ \\
\hline $\begin{array}{l}a \\
b\end{array}$ \\
\hline$c$ \\
\hline$d$ \\
\hline $\begin{array}{l}e \\
f\end{array}$ \\
\hline$g$ \\
\hline
\end{tabular}

Source

Wivelscombe, High Marsh, Tamar

Ernesettle Flat, Tamar

Langton Herring, Fleet

Zostera pools, Maplin Sands, Essex

Brackish pool inside sea wall, Holbeach, the Wash

Lodmoor, Weymouth

Thorn Point Causeway, Tamar

Brackish pool inside sea wall, near Cupid's Corner, Gt Wakering, Essex
New England Creek, Gt Wakering, Essex

$\begin{array}{cc}\begin{array}{c}\text { Length } \\ \text { of } \\ \text { mature } \\ \text { mm. }\end{array} & \text { Collected by } \\ 9.0 & \text { G. I. Crawford } \\ 9.5 & \text { G. M. Spooner } \\ \text { II.0 } & \text { N. H. Howes } \\ \text { I2.0 } & \text { G.M.S. } \\ \text { I } 4.6 & \\ \text { I0.0 } & \text { ", } \\ \text { II.4 } & \text { N.H.H. } \\ \text { I2.0 } & \text { 22.2 }\end{array}$

The localities in the Tamar Estuary mentioned above will be found in a map given by Hartley \& Spooner (1938). 
since comparatively few specimens were available and the range of size in each instar is considerable (Table I). It must be concluded that although the attainment of sexual maturity at a small size, or at an earlier instar than usual, i.e. paedogenesis, causes considerable difference in abdomen shape, other factors, possibly those effecting the precocious onset of sexual maturity, have also some influence on bodily form, for instance, by inducing the early appearance of the median tooth without altering the time of appearance of the postero-lateral angles.

I have pleasure in acknowledging my indebtedness to Prof. H. G. Jackson for much advice, to Mr G. M. Spooner for suggestions and for the loan of much material, to Prof. D. M. S. Watson, F.R.S. for his interest and encouragement and to $\mathrm{Mr} \mathrm{F}$. J. Aumonier for technical assistance in the examination of the aesthetascs. The collecting apparatus used in this work was obtained through a grant from the Government Grants Committee of the Royal Society.

\section{SUMMARY}

A local race of Idotea viridis from south-east Essex is described and its classification as $I$. viridis discussed. This animal is a nektonic form and so far has only been found in New England Creek in south-east Essex. The biology and post-embryonic development of this race is described. Quantitative samples were taken of the animals present in the creek in I934, I935 and 1936. I. viridis was rare in the first five months of the year; numbers rose to a maximum in late June and July and remained comparatively high until the end of October.

The number of young in the brood pouch is very variable. There is some evidence that the number of fertilized eggs was reduced by the expulsion of embryos before their development was complete. The newly hatched I. viridis is described.

There are six ecdyses between hatching and maturity in the males and four or five in the females. The "Przibram quotient" has been calculated between successive instars and there is evidence that the "law of geometrical progression" may be applicable to growth in I. viridis.

Changes in external form during post-embryonic development have been investigated by studying the allometry. Changes in shape not susceptible to measurement are also described. The shape of, and number of aesthetascs on, the flagellum of the antennule change from instar to instar. The number of joints on the flagellum of the antenna also increases progressively. The shape of the abdomen changes and the adult form is only achieved in the last instar of the males. The number of spines on the outer lobe of the maxillula and the ratio breadth/length of the cephalon remain constant throughout the whole post-embryonic development. 
The taxonomic significance of the changes in shape and in proportions is discussed with reference to collections of $I$. viridis made in other parts of England.

\section{REFERENCES}

Bate, C. S. \& Westwood, J. O., I868. A History of the British Sessile-eyed Crustacea, Vol. II. London.

Calman, W. T., I909. Lankester's A Treatise on Zoology, Part vir, Crustacea. London.

Collinge, W. E., I9I7. A revision of the British Idoteidae. Trans. Roy. Soc. Edinb., Vol. LI, pp. 72I-6o.

- 1918. Oral appendages of marine Isopoda. Fourn. Linn. Soc., Vol. 34, pp. 65-93.

Hansen, H. J., I925. Studies on the Arthropoda, Vol. II. Copenhagen.

Hartley, P. H. T. \& Spooner, G. M., I938. The ecology of the Tamar Estuary. I. Introduction. Fourn. Mar. Biol. Assoc., Vol. xxII, pp. $50 \mathrm{O}-8$.

Howes, N. H., 1939. The ecology of a saline lagoon in South-east Essex. Fourn. Linn. Soc., Vol. xL, pp. 383-445.

Huxley, J. S., 1932. Problems of Relative Growth. London.

Huxley, J. S. \& Teissier, G., I936. Terminology of relative growth. Nature, Vol. I37, p. 780 .

Jackson, H. G., I926. The morphology of the isopod head. Part I. Proc. Zool. Soc. Lond., pp. 885-9II.

Jancke, O., I924. Die Brutpflege einiger Malakostraken. Zool. Anz., Bd. LvIII, pp. 273-8.

Needham, A. E., I937. Relative Growth in Asellus aquaticus. Proc. Zool. Soc. Lond. A, pp. $289-3$ I3.

Przibram, H., I93i. Connecting Laws in Animal Morphology. University of London Press.

SARS, G. O., I899. An Account of the Crustacea of Norway, Vol. II, Isopoda. Bergen.

SCHELlENBERG, A., I938. Alters-, Geschlechts- und Individualunterschiede des Amphipoden Niphargus tatrensis. Zool. Fahrb., Abt. I (Systematik), Bd. 7I, pp. I9I-202.

Scourfield, D. J., I896. Olfactory Setae of Cladocera. Fourn. Quekett Micr. Club, Ser. 2, Vol. 6, pp. 280-8.

— I 905 . Die sogenannten "Riechstäbchen" bei den Cladoceren. ForschBer. Biol. Sta. Plön, Bd. I2, pp. 340-53.

TAttersall, W. M., I906. Isopoda. The Marine Fauna of the Coast of Ireland. V. Rep. Sea Inl. Fish. Ireland for 1904, Part II, Appendix No. II.

Zimmer, C., I927. Isopoda, in Kükenthal, W. \& Krumbach, T., Handbuch der Zoologie

Bd. 3. Berlin. 